\title{
NASA Ares I Launch Vehicle Roll and Reaction Control Systems Design Status
}

\author{
Adam Butt ${ }^{1}$ and Chris G. Popp ${ }^{2}$ \\ NASA George C. Marshall Space Flight Center, Huntsville, AL, 35812 \\ Hank M. Pitts ${ }^{3}$ \\ Qualis Corporation, ESTS Group, Huntsville, AL, 35812 \\ and \\ David J. Sharp ${ }^{4}$ \\ Jacobs Engineering, ESTS Group, Huntsville, AL, 35812
}

\begin{abstract}
This paper provides an update of design status following the Preliminary Design Review of NASA's Ares I First Stage Roll and Upper Stage Reaction Control Systems. The Ares I launch vehicle is the selected design, chosen to return humans to the moon, mars, and beyond. It consists of a first stage five segment solid rocket booster and an upper stage liquid bi-propellant J-2X engine. Similar to many launch vehicles, the Ares I has reaction control systems used to provide the vehicle with three degrees of freedom stabilization during the mission. During launch, the First Stage Roll Control System will provide the Ares I with the ability to counteract induced roll torque. After first stage booster separation, the Upper Stage Reaction Control System will provide the upper stage element with three degrees of freedom control as needed. Trade studies and design assessments conducted on the roll and reaction control systems include: propellant selection, thruster arrangement, pressurization system configuration, system component trades, and more. Since successful completion of the Preliminary Design Review, work has progressed towards the Critical Design Review with accomplishments made in the following areas: pressurant/propellant tanks, thruster assemblies, component configurations, as well as thruster module designs, and waterhammer mitigation approaches. Also, results from early development testing are discussed along with plans for upcoming system testing. This paper concludes by summarizing the process of down selecting to the current baseline configuration for the Ares I Roll and Reaction Control Systems.
\end{abstract}

\section{Nomenclature}

$\begin{array}{ll}A D C & =\text { Advanced Development Contract } \\ C A D & =\text { Computer Aided Design } \\ C D R & =\text { Critical Design Review } \\ C E V & =\text { Crew Exploration Vehicle } \\ C x P & =\text { Constellation Program } \\ D A C & =\text { Design Analysis Cycle } \\ D A V & =\text { Direct Acting Valves }\end{array}$

${ }^{1}$ Propulsion Engineer, Spacecraft and Auxiliary Propulsion Systems Branch, ER23, MSFC, AL 35812, AIAA Member.

${ }^{2}$ Sr. Propulsion Engineer, Spacecraft and Auxiliary Propulsion Systems Branch, ER23, MSFC, AL 35812.

${ }^{3}$ Propulsion Engineer, Propulsion Systems Design and Integration, Qualis Corporation, MSFC, AL 35812, AIAA Member.

${ }^{4}$ Sr. Engineering Specialist, Propulsion Systems Design and Integration, Jacobs Engineering, MSFC, AL 35812, AIAA Member. 


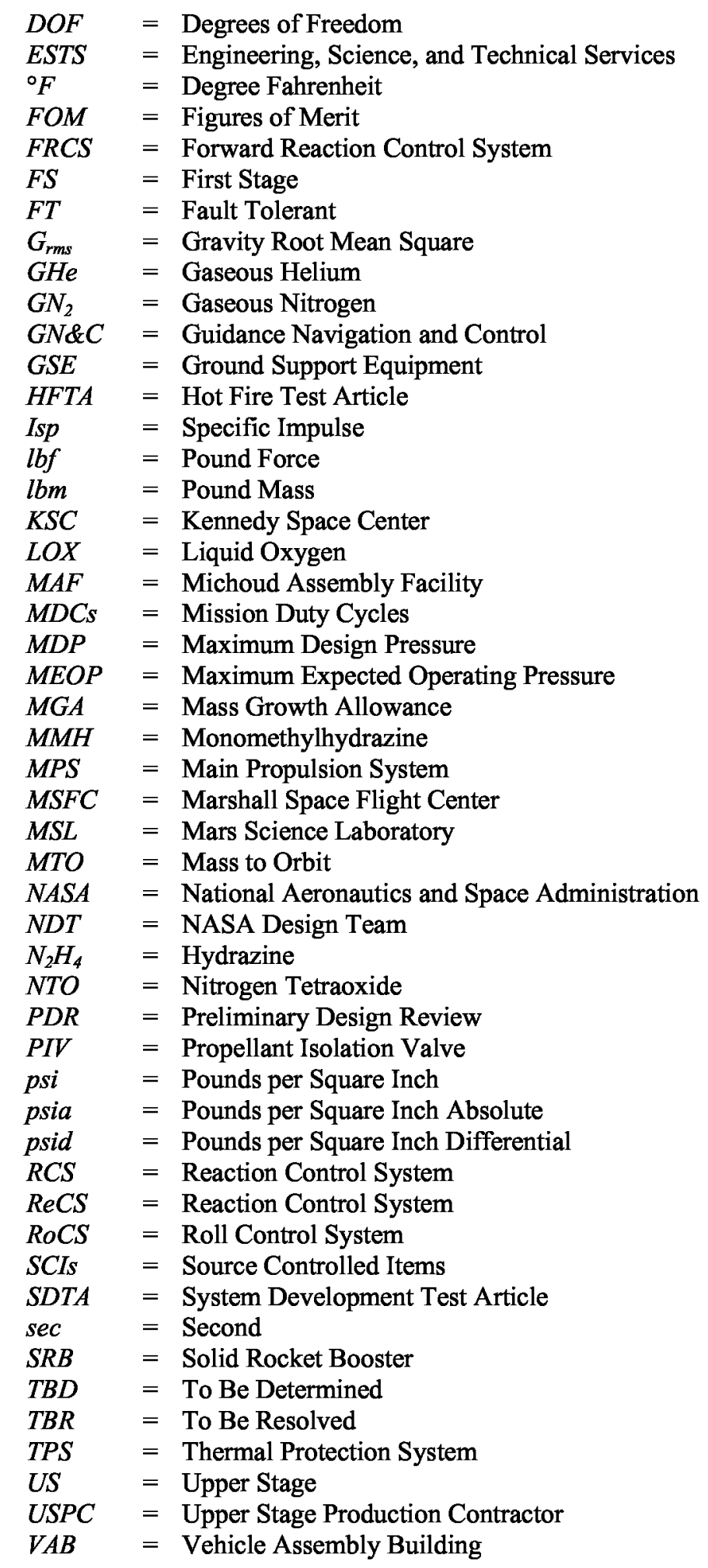

\section{Introduction}

THE Ares I launch vehicle, slated to replace the Space Shuttle for human launches in 2015, is currently in development by the National Aeronautics and Space Administration (NASA) at Marshall Space Flight Center (MSFC) in Huntsville, Alabama, as part of the Constellation Program (CxP). The vehicle designed by the NASA 
Design Team (NDT), with component selection, procurement, and production is handled by the Upper Stage Production Contractor (USPC, Boeing). The Ares I is configured in two inline stages: the First Stage (FS) is a Space Shuttle derived five-segment Solid Rocket Booster (SRB) and the Upper Stage (US) is powered by a Saturn V derived J-2X engine. Roll control for the FS is handled by a dedicated Roll Control System (RoCS), located on the connecting interstage. Any induced yaw or pitch moments are handled by vectoring of the booster nozzle. The FS SRB operates for approximately two minutes after which point the US separates from the vehicle.

Post-separation and prior to the generation of full J-2X thrust, the US Reaction Control System (ReCS) provides three-Degrees of Freedom (DOF) control for the vehicle. After the J-2X ignites, the US ReCS continues to provide roll control for the vehicle. J2-X nozzle vectoring counteracts any induced yaw or pitch moments. Between J2-X engine shutdown and commanded crew vehicle separation, the US ReCS again provides 3-degree of freedom attitude control. The focus of this paper is to describe the early and ongoing design activities related to the FS RoCS and the US ReCS, and also includes updated descriptions of the systems and a brief overview of the test and verification approach. A representation of the Ares I launch vehicle in the stacked configuration with the Orion Crew Exploration Vehicle (CEV) is shown in Figure 1.

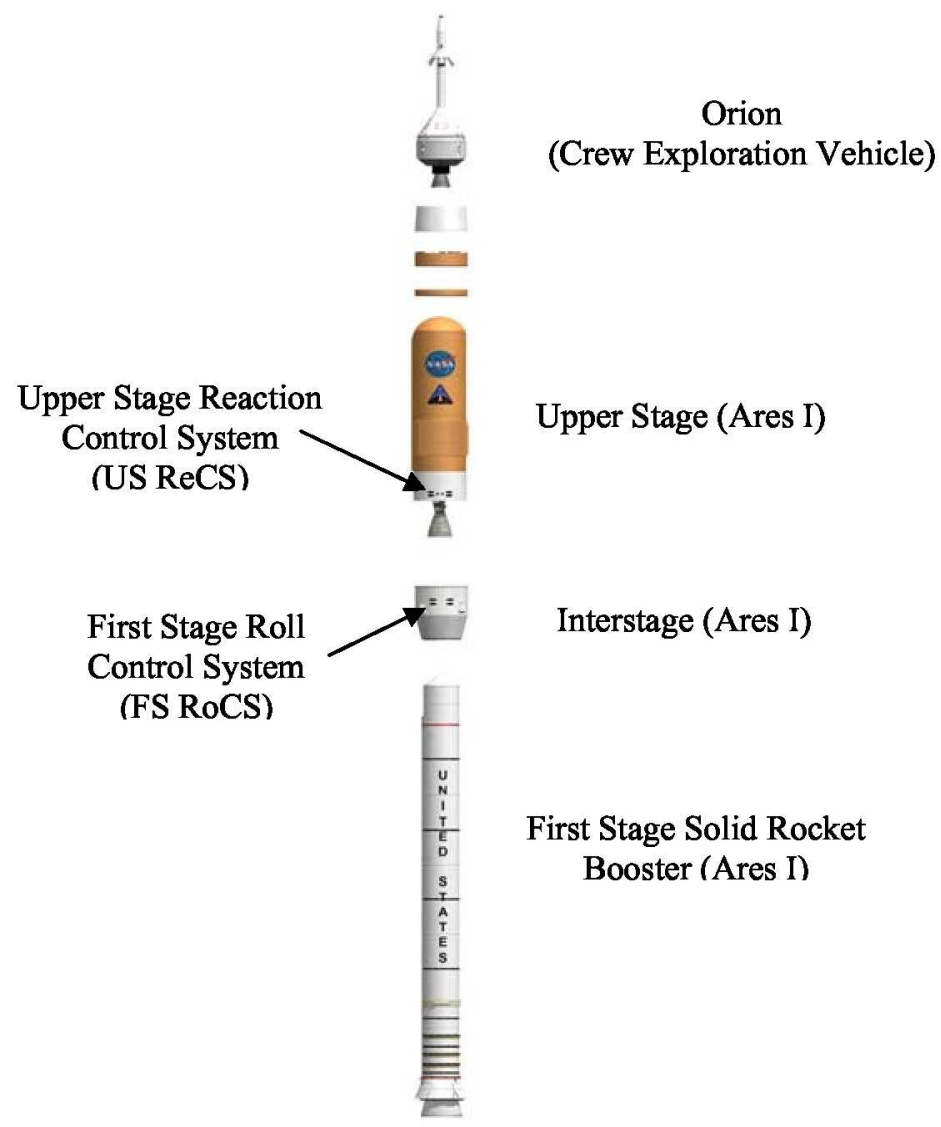

Figure 1. Layout of the Ares I Launch Vehicle and Orion Crew Exploration Vehicle.

\section{A. Ares I Reaction Control System Program Status}

Early planning and design activities began in late 2005 and into early 2006 for the Ares I. In June 2008, the Ares I FS RoCS and US ReCS successfully passed the first major milestone of system design, the Preliminary Design Review (PDR). Based on the current program schedule, the next major design milestone is the Critical Design Review (CDR), which is scheduled for the winter of 2010. Leading up to the CDR the USPC will select and put onto contract a number of vendors for the various Reaction Control System (RCS) components, also known as Source Controlled Items (SCI), to begin the final stages of flight development and qualification. Early development of various SCI is already ongoing and will continue until CDR. Various subsystem and vehicle qualification 
activities will begin after CDR (see Section V for more details) and culminate with the launch of Ares I-Y flight test mission in 2014, which currently requires a fully operational FS RoCS and US ReCS.

\section{First Stage Roll Control System}

\section{A. Mission Overview}

The Ares I incorporates a RoCS which contains the necessary performance capabilities and associated hardware to perform roll control operations during active FS flight operations. Pitch or yaw moments generated during FS operation are counteracted via vectoring of the booster motor nozzle. The FS RoCS is a single use system that is located on the interstage portion of the vehicle and will fall back to Earth after FS solid rocket motor burnout and FS separation from the US. FS separation occurs approximately two minutes after launch.

\section{B. Subsystem Description}

The FS RoCS design incorporates a distributed, pressure-regulated Gaseous Helium (GHe) pressurization system, with localized sets of propellant tanks in a monopropellant Hydrazine $\left(\mathrm{N}_{2} \mathrm{H}_{4}\right)$ propulsion system. The FS RoCS configuration has two thruster modules that are $180^{\circ}$ apart, with a set of localized propellant tanks located behind each thruster module on the inside surface of the interstage. The overall FS RoCS architecture includes: pressurant loading, pressurant storage, pressurant regulation and isolation, propellant loading, propellant storage, consumable acquisition, propellant delivery, and thrusters to deliver the required impulse and moment generation capability. This architecture provides one failure tolerance for function and prevention of catastrophic hazards, such as inadvertent thruster firing, bulk propellant leakage, and over pressurization.

The pressurization system includes two regulators referenced to ambient pressure on parallel strings to attain the required system level single Fault Tolerant (FT) for function. A single burst disk and relief valve assembly is included to ensure single failure tolerance for must-not-occur catastrophic hazards.

The system is designed to support the firing of multiple thrusters simultaneously as required to counteract roll torque disturbances. Each thruster module contains six 625 -lbf thrusters (three each in the positive and negative roll directions), including four primary and two secondary thrusters. The design of six thrusters per thruster module is predicated on avionics providing command and control capability such that no single avionics failure results in the loss of more than a single pair of $+/$ - roll thrusters in each thruster module. The thruster design is derived from a heritage NASA Jet Propulsion Laboratory Mars Lander Engine positioned configuration, with an associated flowrate of approximately $3.0 \mathrm{lbm} / \mathrm{sec}$ at the rated thrust. All thrusters are in an inline configuration (catalyst chamber and nozzle); with nozzle centerlines being parallel to the Y-Z plane of the vehicle. Each thruster is canted $20^{\circ}$ relative to the tangent surface of the interstage outer wall, at the thruster module centerline point, in order to reduce plume thermal effects and subsequent interstage Thermal Protection System (TPS) mass. The baseline design incorporates series redundant, pneumatically actuated thruster valves.

The design of each thruster module includes a base plate, thruster mounting bracket, and fairing enclosure. Features include insulated and thermally isolated thrusters, as well as individual thruster to fairing closeouts to prevent external aerodynamic flow into, and external heating of, the thruster module. Titanium and aluminum are prevalent throughout the thruster module structure. Additionally, a single access panel has been added to the outboard surface of each thruster module, primarily to add access to the main structure of the thruster modules for assembly purposes. Vibration isolators are incorporated in the thruster assemblies and the sub-assembly panels (service panel and pressurant panel) to dampen the vibration loads from the interstage wall.

The initial design approach for the Ares I FS RoCS was an all-welded design, however to facilitate checkout and final assembly, mechanical fittings have been added to various locations throughout the system. In the pressurization and pneumatic system, fittings have been added to the pneumatic inlet on the thruster control valves. All pressurant and propellant tanks also employ mechanical flange interfaces.

Propellant is stored in four supply tanks, with two located in a localized configuration behind each thruster module on the inside of the interstage structure. Propellant tanks are of an all-metal cylindrical design, with elastomeric diaphragms for positive expulsion. The total propellant mass is approximately $1136 \mathrm{lbm}$ with $40 \mathrm{lbm}$ of unusable hold up volume. Volume and dry mass for each propellant tank is approximately 8115 cubic inches (in ${ }^{3}$ ) and $40.0 \mathrm{lbm}$. Nominal and Maximum Expected Operating Pressure (MEOP) are approximately 639 and 843 psia respectively. The distributed pressurization subsystem is located along the inner wall of the interstage, approximately halfway between the thruster modules and the three high pressure helium storage tanks. Each of the high pressure, cylindrical composite over-wrapped GHe pressurant tanks are sized to operate at a maximum helium pressure of 4500 psia. Each pressurant tank is approximately $8438 \mathrm{in}^{3}$ with an estimated weight of $74.0 \mathrm{lbm}$. The total amount of GHe loaded is estimated at $35 \mathrm{lbm}$, with $21.5 \mathrm{lbm}$ of that total unusable. The high percentage of 
unusable pressurant is due to end of mission pressure and temperature constraints and the rapid mission usage timeline. Tank dome diameters are based on heritage vendor tooling. A common pressurant system is used for pressurization of the propellant tanks and actuation of the pneumatic thruster valves due to commonality of operating pressure levels and for system simplicity. Additionally, helium manual valves and service valves are added to facilitate propellant loading of the localized propellant tanks from the service panel.

The FS RoCS configuration is designed to facilitate draining, purging, and decontamination of the propellant system. The service panel (which contains the fill/drain valves) is located on the outside of the interstage wall to give access to the service valves from outside the vehicle. A liquid trap/low point is located on the propellant fill/drain lines. A purge line is located at the top of each thruster module and routed back to the service panel. Two service valves, one for the $+Z_{S}$ thruster module and one for the $-Z_{S}$ thruster module, provide a continuous circuit for purging the system. The propellant manifold is designed to facilitate faster draining. The outer diameter of the fill/drain line is $1 / 2$ " to ensure adequate drain and decontamination performance.

To provide compliance for the system to misalignments, tolerance stack up, vibrations and other loads, flex lines are installed at the inlets and outlets of each propellant tank and where the propellant line passes across the interface between interstage and the thruster module. A split manifold has been placed in the thruster module to feed propellant to the thrusters. The manifold is mounted to the thruster mounting plates so that, in conjunction with the flex lines, the vibrations loads from the lines do not restrict the thruster vibration isolators.

The approach of the CxP has been to require encompassing transient system pressures into the definition of Maximum Design Pressure (MDP), which is the value from which proof and burst pressure levels are determined. In general, higher proof and burst pressures usually result in more complex, heavier, and more expensive components. It is therefore desirable to minimize the MDP, and the FS RoCS incorporates a few design features to help mitigate the transient (waterhammer) pressure levels. The design features include large manifold line sizes with increased propellant feed line wall thickness, localized propellant tanks to minimize propellant line lengths and staggered thruster closing times to minimize wave amplification. Analysis of the design gives a propellant system MDP of $1250 \mathrm{psia}$. MDP is defined as the MEOP plus the affects from waterhammer surges. System fluid analysis was performed using the MSC software Easy $5^{\mathrm{TM}}$ to provide preliminary operating condition estimates.

The system pressure budget includes: both nominal and 1-FT component pressure drops, regulator set pressure accuracy $( \pm 4.0 \%)$, relief valve cracking and full flow pressure settings. Of special note, the regulator set pressure (and subsequently the MEOP, MDP, tank pressure, and thruster valve inlet pressure) is based on the component pressure drops associated with a 1-FT operating condition. This is to ensure that the desired $625 \mathrm{lbf}$ thrust level is achieved in any single failure scenario. Two 1-FT scenarios are tracked: the propellant filter at maximum holding capacity resulting in an increased fluid pressure drop, and a failed regulator which drives the pressure to MEOP before switching to the redundant regulator. Under nominal operating conditions, the pressure drop across all feed system components is lower than each of the two 1-FT cases. The outcome is a high propellant pressure at the thruster valve inlet resulting in high nominal expected thrust (approximately $632 \mathrm{lbf}$ ). A summary of the FS RoCS expected nominal and 1-FT pressure drops and pressure budget are presented in Tables 1 and 2.

Table 1. Estimated Component Pressure Drop Nominal Values and Expected Ranges for Various 1-Fault Tolerant Conditions.

\begin{tabular}{|r|c|c|}
\hline Component & $\begin{array}{c}\text { Nominal } \\
\text { Pressure Drop } \\
{[\mathrm{psid}]}\end{array}$ & $\begin{array}{c}\text { Expected } \\
\text { Pressure Drop } \\
\text { Range [psid] }\end{array}$ \\
\hline Regulator to Tank Line $=$ & 12 & $10-14$ \\
\hline Tank Isolation Valve $=$ & 5 & $4-6$ \\
\hline Tank Pressure [psig] $=$ & 639 & $613-793$ \\
\hline Tank Outlet $=$ & 2 & $2-3$ \\
\hline System Filter $=$ & 3 & $9-14$ \\
\hline Line loss $=$ & 19 & $18-27$ \\
\hline Flexline - Tank Outlet $=$ & 3 & $3-4$ \\
\hline Flexline - Interstage to Thruster Module $=$ & 4 & $4-5$ \\
\hline Thruster Valve Inlet [psia] $=$ & 593 & $562-737$ \\
\hline
\end{tabular}


Table 2. First Stage Roll Control System Pressure Budget.

\begin{tabular}{|c|c|c|}
\hline & $\%$ Tolerance & DAC2B E \\
\hline \multicolumn{3}{|l|}{ GHe Supply } \\
\hline Inlet Supply Min [psia] = & & 1500 \\
\hline Inlet Supply@160F [psia]= & & 4500 \\
\hline \multicolumn{3}{|l|}{ Regulator } \\
\hline Operating (Nominal) $[\mathrm{psia}]=$ & & 656 \\
\hline Operating Min [psia] $=$ & $-4.0 \%$ below nom. & 629 \\
\hline Operating Max [psia] $=$ & $4.0 \%$ above nom. & 682 \\
\hline Lock Up [psia] $=$ & $7.0 \%$ above nom. & 702 \\
\hline Maximum Overshoot [psia] $=$ & $7.0 \%$ above nom. & 702 \\
\hline \multicolumn{3}{|l|}{ Burst Disk } \\
\hline Minimum BD Rupture [psia] = & $\begin{array}{l}4.0 \% \text { above Reg. } \\
\text { overshoot }\end{array}$ & 730 \\
\hline Maximum BD Rupture [psia] = & $\begin{array}{l}8.0 \% \text { above } \min \\
\text { rupture }\end{array}$ & 788 \\
\hline \multicolumn{3}{|l|}{ Relief Valve } \\
\hline Minimum RV Reseat [psia] $=$ & $\begin{array}{l}3.5 \% \text { above Reg. } \\
\text { overshoot }\end{array}$ & 726 \\
\hline Minimum RV Cracking [psia] = & $\begin{array}{c}3.5 \% \text { above } \min \mathrm{RV} \\
\text { reseat }\end{array}$ & 752 \\
\hline RV Full Flow Pressure [psia] $=$ & $\begin{array}{c}5.0 \% \text { above } \min \mathrm{RV} \\
\text { cracking }\end{array}$ & 789 \\
\hline $\begin{array}{l}\text { High Pressure GHe MEOP and MDP } \\
\text { [psia] }\end{array}$ & & 4500 \\
\hline $\begin{array}{l}\text { Upstream Low Pressure GHe MEOP } \\
\text { [psia]* }\end{array}$ & & 843 \\
\hline $\begin{array}{l}\text { Downstream Low Pressure GHe and } \\
\text { Propellant MEOP** [psia] }\end{array}$ & & 793 \\
\hline Propellant MDP*** [psia] & & 1250 \\
\hline
\end{tabular}

In order to maintain thruster module temperatures within acceptable ranges prior to operation, a thermal conditioning system has been added to the FS RoCS. The thermal conditioning system consists of a warm Gaseous Nitrogen $\left(\mathrm{GN}_{2}\right)$ /air purge from the Environmental Conditioning System, a series of tank, line, and thruster module wall heaters, and insulation. The purge enters from the interstage to the thruster modules through a 1.0" port at 50 standard cubic feet per minute (scfm), $60^{\circ} \mathrm{F}$ nominal, and exits back to the interstage via a secondary port. The set points are $90^{\circ} \mathrm{F} \pm 5^{\circ} \mathrm{F}$ for the propellant and pressurant tank and line heaters and $70^{\circ} \mathrm{F} \pm 15^{\circ} \mathrm{F}$ for the fairing heaters. The insulation used on both the tanks and lines is $1.0^{\prime \prime}$ thick Fiberfrax ${ }^{\circledR}$ with Astroquartz ${ }^{\circledR}$ inner and outer coverings.

The FS RoCS architecture is predicted to utilize a peak flight power load of 855.46 Watts, as shown in Table 3. In addition, in order to maintain thruster module temperatures within acceptable ranges prior to operation, the FS RoCS incorporates a thermal conditioning system. The thermal conditioning system consists of a warm $\mathrm{GN}_{2} /$ air purge, a series of tank and line heaters, catalyst bed heater and insulation. The purge gas enters from the interstage to the thruster modules and exits back to the interstage via a separate port. Allowable pre-flight temperature requirements have been set at $90 \pm 5^{\circ} \mathrm{F}$ for the propellant and pressurization sections of the system. 
Table 3. First Stage Roll Control System Flight Power Requirements.

\begin{tabular}{|c|c|c|c|c|c|}
\hline Component & FS Total & $\begin{array}{l}\text { FS Total } \\
\text { Under } \\
\text { nominal } \\
\text { Operation }\end{array}$ & $\begin{array}{l}\text { Estimated } \\
\text { Peak } \\
\text { Current } \\
\text { Required } \\
\text { Amps }\end{array}$ & $\begin{array}{c}\text { Estimated } \\
\text { Peak Power } \\
\text { Required } \\
\text { Watts }\end{array}$ & $\begin{array}{c}\text { Estimated time } \\
\text { of operation at } \\
\text { peak draw in } \\
\text { seconds }\end{array}$ \\
\hline Temperature Transducers & 72 & 72 & 0.072 & 2.02 & 186 \\
\hline Pressure Transducers & 16 & 16 & 0.48 & 13.44 & 186 \\
\hline $\begin{array}{l}\text { Normally Closed (NC) } \\
\text { Solenoid Valves (Helium } \\
\text { Isolation Valves) }\end{array}$ & 2 & 2 & 6.00 & 168.00 & 186 \\
\hline $\begin{array}{l}\text { NC Pneumatic Solenoid } \\
\text { Valves* (Thruster Control } \\
\text { Valves) }\end{array}$ & 24 & 12 & 24.00 & 672.00 & 70 \\
\hline $\begin{array}{l}\text { Total Estimated Power for FS } \\
\text { RoCS (without position } \\
\text { sensors) }\end{array}$ & & & & 855.46 & \\
\hline
\end{tabular}

* Assumes 12 valves actuated (6 thrusters firing). There exists enough fuel for $\sim 63$ seconds of run time with 6 thrusters firing. There is an additional $10 \%$ applied to the firing time for overhead. Mission profiles show $\sim 186 \mathrm{sec}$ total duration of FS system from T-60 to FS SRB separation.

Due to the RoCS being jettisoned with the FS, the Mass-to-Orbit (MTO) turn down ratio is approximately 10:1, meaning that for every $10 \mathrm{lbs}$ of system mass, $1 \mathrm{lb}$ of potential payload is lost. The FS RoCS is, therefore, not as sensitive to mass as the US ReCS which is located on the Upper Stage (and thus having a direct 1:1 effect on MTO). Mass is, however, as with any spacecraft, a critical consideration of vehicle design. FS RoCS mass estimates are shown in Table 4. The Design Analysis Cycle - 3A_Start RevisonA (DAC-3A_S_RevA) FS RoCS schematic key is shown in Figure 2 and the DAC-3A_S_RevA FS RoCS schematic is shown in Figure 3. The Computer Aided Design (CAD) layout and physical dimensions for the FS RoCS are provided in Figure 4 and Table 5, respectively.

Table 4. Design Analysis Cycle-3A_Start_Revision C First Stage Roll Control Systems Estimated Mass Properties.

\begin{tabular}{|c|c|}
\hline FS RoCS Mass Properties Rollup & (lbm) \\
\hline \multicolumn{2}{|l|}{ Dry Mass } \\
\hline (I.) Structure & 456.4 \\
\hline (II.) Pressurant/Propellant Tanks & 382.0 \\
\hline (III. \& IV.) Components and Miscellaneous & 308.7 \\
\hline (V.) Thrusters & 324.0 \\
\hline Total Dry Mass (w/o MGA) & 1471.1 \\
\hline \multicolumn{2}{|l|}{ Wet Mass } \\
\hline \multicolumn{2}{|l|}{ (VI.) Consumables } \\
\hline A. GHe Pressurant & 35.0 \\
\hline B. Ascent Propellant & 1096.0 \\
\hline C. Residual Propellant & 40.1 \\
\hline Total Wet Mass (w/o MGA) & 1171.1 \\
\hline Total FS RoCS Mass (w/o MGA) & 2642.2 \\
\hline
\end{tabular}




$\begin{gathered}\text { Change in Line } \\ \text { Size }\end{gathered}$
Service Valve
$\begin{gathered}\text { Helium Manual Valve } \\ \text { Helium Isolation Valve } \\ \text { (With Integral Fiter) }\end{gathered}$

Figure 2. Design Analysis Cycle - 3A_Start_Revision A First Stage Roll Control System Schematic Key.

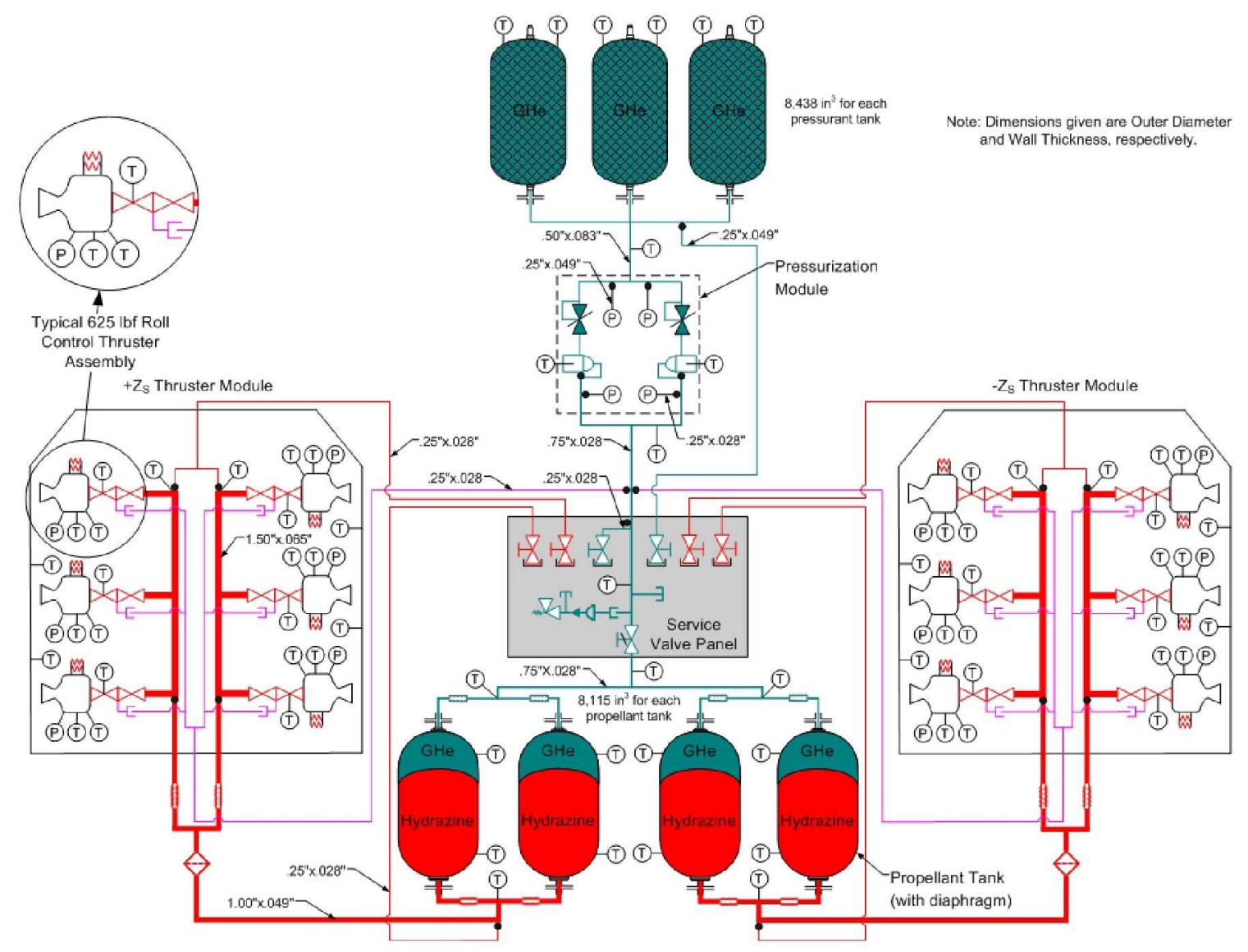

Figure 3. Design Analysis Cycle - 3A_Start_Revision A First Stage Roll Control System Schematic. 8

American Institute of Aeronautics and Astronautics 


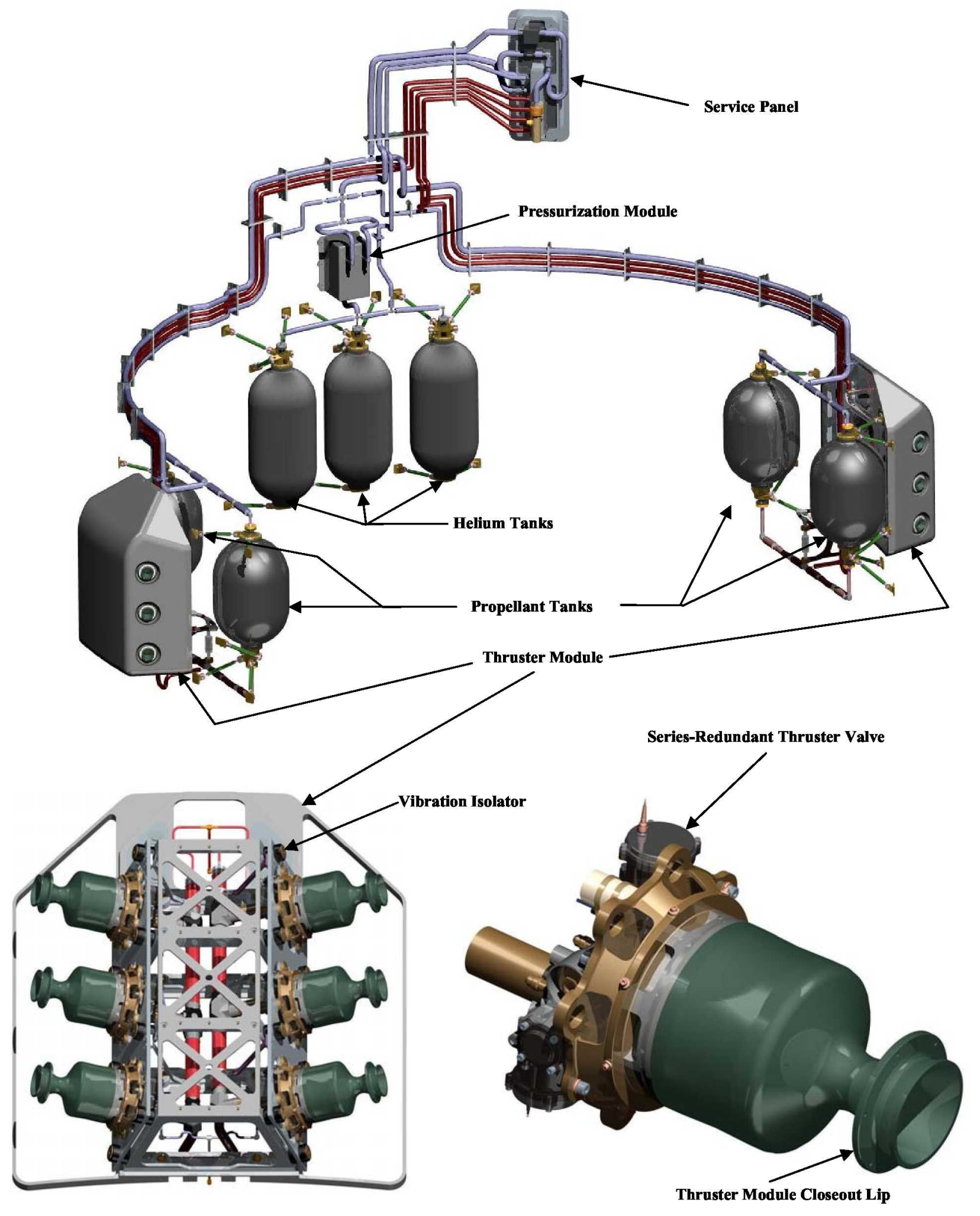

Figure 4. First Stage Roll Control System Baseline Computer Aided Design Models. 
Table 5. First Stage Roll Control System Preliminary Design Review Approximate General Dimensions.

\begin{tabular}{|l|l|}
\hline \multicolumn{2}{|c|}{ General First Stage Dimensions } \\
\hline Pressurant Tank - Cylindrical COPV & \\
\hline Diameter & $18.5^{\prime \prime}$ ID \\
\hline Length & $39.6^{\prime \prime}$ ID \\
\hline Propellant Tank - Cylindrical Metal & \\
\hline Diameter & $21.25^{\prime \prime}$ ID \\
\hline Length & $30^{\prime \prime}$ ID \\
\hline Thruster Module & \\
\hline Height & $48.7^{\prime \prime}$ \\
\hline Width & $40.0^{\prime \prime}$ \\
\hline Depth & $17.4^{\prime \prime}$ \\
\hline Approximate Line Lengths & \\
\hline Pressurant Tank to Propellant Tank & $1159^{\prime \prime}$ \\
\hline Propellant Tank to Thruster Valve & $196^{\prime \prime}$ \\
\hline
\end{tabular}

\section{Subsystem Requirements and Anticipated Environments}

The FS RoCS must be capable of counteracting a maximum of $1150 \mathrm{ft}$-lbf of torque (vacuum conditions), per the current requirements of Guidance, Navigation and Controls (GN\&C). The currently baseline FS RoCS incorporates twelve $625 \mathrm{lbf} \mathrm{N}_{2} \mathrm{H}_{4}$ monopropellant thrusters. Thrusters are arranged in +Roll and -Roll pairs in two diametrically opposed thruster modules on the outside of the interstage wall. Thrusters utilize a 5:1 expansion ratio configuration to decrease overall thruster module size and associated mass.

Currently, one of the largest challenges with the design and development of the RCS (both RoCS and ReCS) are the predicted environments. The vibration levels (and shock for ReCS) that both systems will need to survive, and the RoCS operate in, are at the high end of or exceed previous experience and heritage for these types of monopropellant systems even after the incorporation of vibration isolation systems. There is very little historical precedence for high flow rate, pulsed-mode monopropellant thrusters operating during the high aerothermal and aero-acoustic booster phase of a launch vehicle operation.

\section{Propulsion System Design Assessments and Trade Studies}

The following sections detail the various design trade studies undertaken by the RCS NDT through various design cycles. The design changes are captured in formal DAC, with descriptions in this paper beginning at DAC$1 \mathrm{~A}$ and concluding with DAC-3A_S_RevC. The studies are listed in approximately chronological order. The emphasis of the trade studies has been to develop a system design driven primarily by a high amount of safety, low mass, low cost, and high heritage.

\section{Propellant Selection}

The initial baseline for the FS RoCS was a bi-propellant, hypergolic Monomethyl Hydrazine (MMH) and Nitrogen Tetroxide (NTO) architecture, despite the recognized simplicities inherent in monopropellant architectures. The primary rationale for the original decision was that there existed a number of flight heritage pulse-mode bipropellant thrusters which could have been arranged in various combinations to achieve the required thrust levels (i.e. two 800 -lbf or three $400-\mathrm{lbf}$ thrusters to achieve the required $\sim 1200-\mathrm{lbf}$ per moment arm). At the beginning of the design cycles there were not any high thrust monopropellant thrusters that had been used in pulse-mode operations with flight or development level heritage. Further trade studies were conducted during DAC-1B and DAC-1C to continue the assessment of monopropellant verses bi-propellant architectures.

\section{Bi-Propellant Purge System}

Previous experience with the baselined MMH/NTO thruster combination used in a pulsing fashion within the atmosphere indicated the need for a purge system. The reason for a purge system was that during pulse mode operation fuel and oxidizer vapors can linger in the combustion chamber due to the atmospheric pressure, and can potentially mix and detonate within the injector cavities. This phenomena, also known as intramanifold propellant reactions and also as 'zots' or 'zotting', can impact system performance or cause a critical failure. Therefore in order 
to eliminate the potential unwanted accumulation and mixing of the hypergolic propellants, a purge system was deemed necessary for a FS RoCS pulsing MMH/NTO thruster. A trade study was then conducted to ascertain a purge system architecture with minimal impacts to the overall FS RoCS. The following parameters were included in the trade space:

- Constant, checked purge throughout mission.

- Short sweep purge after each thruster pulse.

- Purging both the fuel and oxidizer manifolds.

- Purging either the fuel or oxidizer manifolds.

- Centralized, separate centralized or distributed purge architectures, (Figure 5).

- Low, moderate, or blowdown purge flowrates.
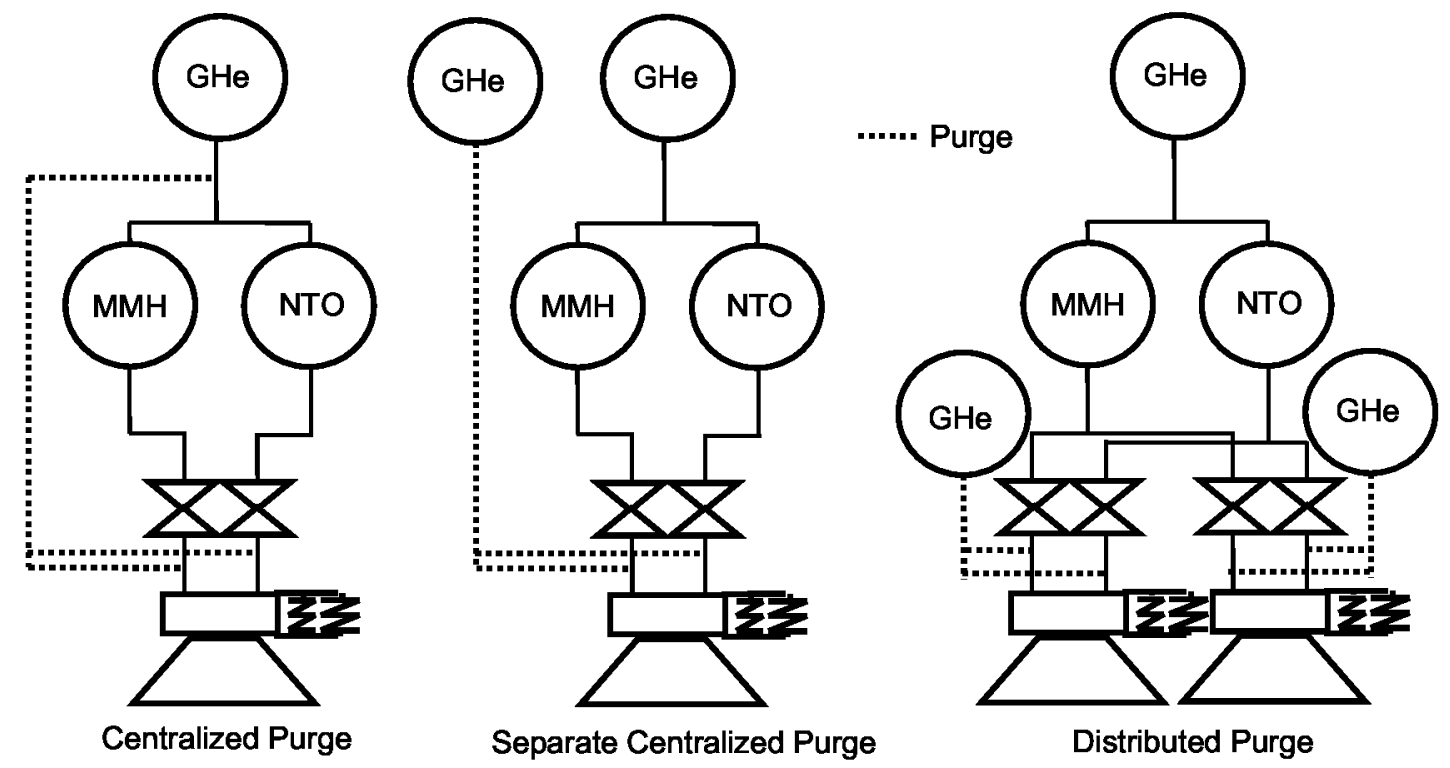

Figure 5. Simplified Representations of Centralized, Separate Centralized and Distributed Purge Architectures.

A relative comparison was conducted using mass, cost, ground operations, failure sensitivity, and reliability as Figures of Merit (FOM). The results recommended separate centralized purge architecture, incorporating blowdown sweep purges of both the fuel and oxidizer passages. This solution greatly complicated the design of the FS RoCS, but was determined as necessary for operation of a MMH/NTO engine during the FS mission.

\section{Thruster Testing Results}

In December 2006, a series of thruster tests were performed on a high thrust-class monopropellant $\mathrm{N}_{2} \mathrm{H}_{4}$ engine. The engine was a derivative of the Mars Science Laboratory (MSL) decent engine, which itself is a derivative of the Viking Mars lander engine. The purpose of the testing was to demonstrate the pulse mode operation of a high thrust class monopropellant engine, for which there was very little existing data (existing data in this thrust class was predominantly steady state or throttling).

Testing was successfully completed with a total propellant throughput equivalent to nearly two FS RoCS missions, with no significant degradation in thruster performance. Test results provided a high level of confidence in the feasibility of a high thrust, pulse mode $\mathrm{N}_{2} \mathrm{H}_{4}$ thruster capable of satisfying FS RoCS requirements with margin.

\section{Bi-Propellant vs. Monopropellant}

Despite the monopropellant architecture scoring higher in a previous trade study (see 'System Arrangement' below) the bi-propellant architecture was baselined and carrying through the conclusion of DAC-1. The primary reason for this previous selection was the limited historical data, as well as the perceived technical and schedule risk associated with a high thrust level pulsing monopropellant engine. The perceived risks were mitigated in December, 
2006 with the successful pulse mode demonstration of a high thrust class monopropellant engine, which prompted a revisit of the trade study between the baselined bi-propellant and a monopropellant system. The FOMs used for the relative comparison between the two options were as follows:

- Technical

○ Mass, power, reliability, flight safety, ground safety

- Cost

- Development costs, production costs, recurring costs

- Risk

- Schedule, hardware development

The areas that scored higher for the bi-propellant system included higher performance and greater thrust margins, based on previously produced higher thrust engines. The areas that scored higher for the monopropellant system included cost, schedule, power, avionics requirements, system complexity, processing and serviceability. Mass did not end up being a significant driver one way or another as the bi-propellant system required a zots mitigation purge system, and the monopropellant system required additional propellant to make up for lower efficiency. Additional factors that ended up being in favor of the monopropellant system included reducing the total number of propellants needed to be loaded at the launch pad $\left(\mathrm{N}_{2} \mathrm{H}_{4}\right) / \mathrm{MMH} / \mathrm{NTO}$ vs. $\mathrm{N}_{2} \mathrm{H}_{4}$ (when considering all Ares I attitude control systems), as well as a greatly simplified system architecture, without a thruster purge system. The recommendation of the trade study was, therefore, to replace the bi-propellant FS RoCS with a monopropellant $\mathrm{N}_{2} \mathrm{H}_{4}$ system, incorporating 12 total thrusters at a thrust level of $625 \mathrm{lbf}$, located in two thruster modules.

\section{System Architecture}

The objective of one of the first large trade studies conducted during DAC-1A was to identify and evaluate overall system architecture designs. Design options included monopropellant $\mathrm{N}_{2} \mathrm{H}_{4}$ and bi-propellant (MMH/NTO) architectures, $100 \mathrm{lbf}$ and $800 \mathrm{lbf}$ thrusters, as well as modular (tank and thrusters located in two sets, $180^{\circ}$ apart), distributed (thruster modules located $180^{\circ}$ apart manifolded to tanks located in the center), and pod (two thruster pods located $180^{\circ}$ apart, each completely contained with thrusters, tanks and components) system architectures. The design space did not include non-toxic propellant and gas generator architectures, due to their low Technology Readiness Level for human-rated spaceflight applications.

The ground rules for the trade study were that the system should be 1-FT for nominal operation and 2-FT catastrophic flight and ground safety (such as three barriers to inadvertent firing), and $800 \mathrm{lbm}$ of useable propellant assuming bi-propellant performance characteristics. The FOMs used to evaluate the various configurations included mass, costs (development, production, recurring), risks (schedule and development), and flight and ground safety. The results from the trade study recommended that distributed bi-propellant architecture with sixteen $800 \mathrm{lbf}$ thrusters (full thruster redundancy) would best satisfy the baseline requirements. The distributed monopropellant architecture scored higher but was not baselined at the time due to perceived technical risk associated with large pulsing $\mathrm{N}_{2} \mathrm{H}_{4}$ thrusters. The final recommendation of the trade was, however, to continue evaluating both distributed bi-propellant and monopropellant architectures.

\section{Mechanical Regulators us. Bang-Bang Valves}

The focus of this study was to analyze and trade the pressure regulation architecture, considering mechanical regulators and electronically controlled bang-bang valves (also known as control valves). Bang-bang valves are typically two solenoid valves in series, the first is used as an isolation valve and the second to control downstream pressure. The downstream pressure is regulated via a computer controlled feedback loop. Pressure transducers downstream of the pressure regulation devices report the ullage pressure to the pneumatic controller which commands the bang-bang valves to open and close to maintain a desired pressure. A simplified schematic of a bang-bang valve pressure regulated system is shown in Figure 6. 

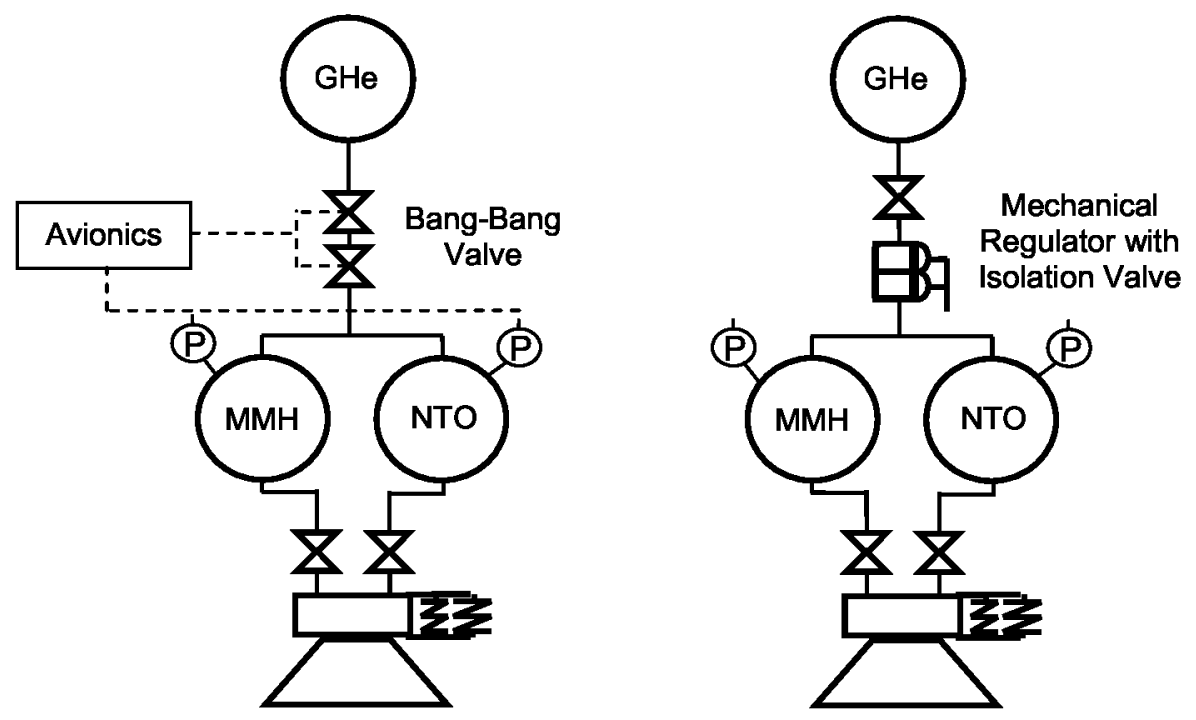

Figure 6. Simplified Bang-Bang Regulated and Mechanically Regulated Pressurization System Diagrams.

The recommendation of the trade study was to retain the mechanical regulators as the baseline method of pressure regulation. The FOMs leading to this decision included system complexity, impacts to the avionics architecture for an autonomous bang-bang valve controller, avionics and power requirements, and reliability.

\section{Direct Acting Solenoid vs. Pneumatic Thruster Valves}

A FS RoCS trade study was conducted to ascertain the system impacts of replacing the direct acting solenoid thruster valves with pneumatically operated thruster valves. Direct Acting Valves (DAV) was the baselined thruster valve at the beginning of DAC-1C_S. Many different pneumatic system architectures were developed and analyzed to find a system that had the least impacts to the baseline FS RoCS. Architectures were considered in which additional GHe was supplied by the main GHe tanks as well as by separate GHe tanks. Pneumatic actuation pressure was also evaluated to determine whether or not it was essential to have thruster pneumatic pressure equal to the operation pressure of the propellant tanks. A relative comparison was conducted using mass, cost, operability, and technical risk as FOMs and the results indicated that pneumatic thruster valves were a better option than DAVs.

\section{Manifold Isolation vs. Series Redundant Thruster Valves}

In order to address concerns with a few design issues (surge pressures upstream of isolation valve, surge arrestor configuration, etc.), the arrangement of the thruster valves and Propellant Isolation Valves (PIV) was re-assessed. The baseline configuration at the start of DAC-2 had six thrusters per thruster module, with pairs of plus and minus roll thrusters being manifolded together. Each thruster pair, with a single wet valve per thruster, was then separated from the propellant tank by a PIV. A relative comparison was made comparing the baseline approach of isolating pairs of thruster to isolating each individual thruster with series redundant thruster valves. A basic schematic of the two configurations is shown in Figure 7. 


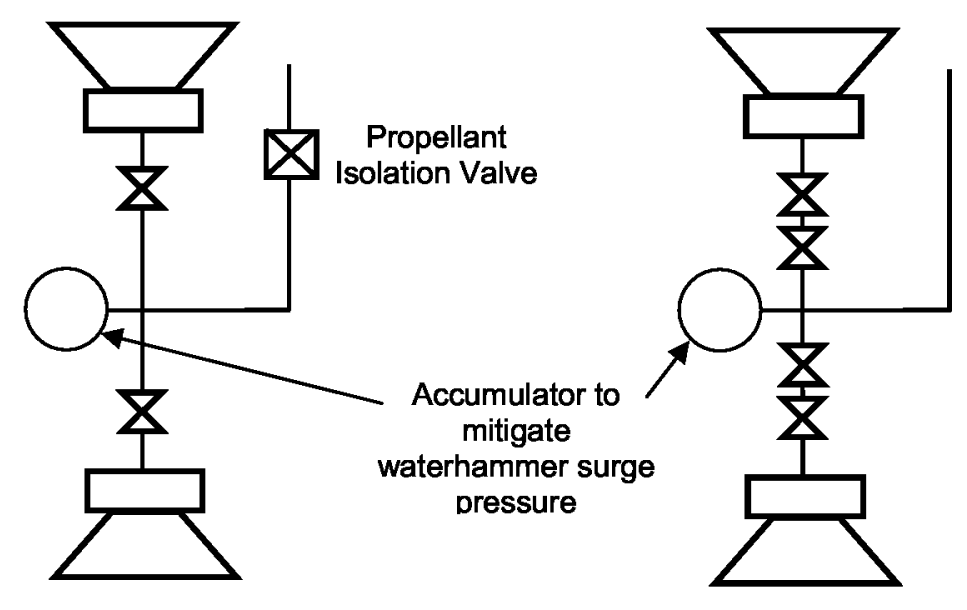

Figure 7. Manifold isolation (left) and Series Redundant Valve (right) Configurations.

Design issues associated with the manifold isolation approach included the following:

- No method or design feature to mitigate a waterhammer surge pressure upstream of the PIV in case of a fail close scenario, which could potentially damage the valve soft goods.

- Location of the PIV would force additional design constraints related to reverse flow and back pressure relief.

- A single failure downstream of the PIV would cause the loss of two thrusters.

The perceived advantages of serial thruster valves included the following:

- Isolation of individual thrusters in the advent of a failure.

- Decreased risk of inadvertent thruster firing - with both valves normally closed the potential for an inadvertent thruster firing on the ground is reduced.

- Increased commonality in components, (decrease in development costs).

- Possible combination of both valves into a single, lower mass, volume, and cost package.

- Similarity with the Ares I US ReCS and other existing satellite systems.

The FOMs used for the relative comparison of the configurations included mass, cost, power and avionics, ground operations, reliability, and safety. The recommendation from the trade study was to change from a manifold isolation to a series redundant thruster valve approach.

\section{Waterhammer Surge Pressure Mitigation}

As previously mentioned, transient surge pressures (including waterhammer surge pressures associated with rapid valve closing) are encompassed under the MDP. Various design assessments and trade studies were conducted to evaluate various methods to mitigate the maximum expected surge pressure. Fluid analysis results were generated using MSC Software Inc. EASY5 ${ }^{\mathrm{TM}}$.

\section{Localized Propellant Tanks}

To develop a system level waterhammer mitigation approach, a trade study was conducted to evaluate distributed propellant tank architecture in comparison to localized propellant tank architecture. A top view, cross-sectional schematic of the two configurations is shown below in Figure 8. In the distributed tank architecture, the total propellant is contained in three tanks located in between the two thruster modules. The localized tank architecture splits the total propellant quantity in half and the propellant is contained in two sets of two tanks that are "localized" to each thruster module. 
Distributed Tanks

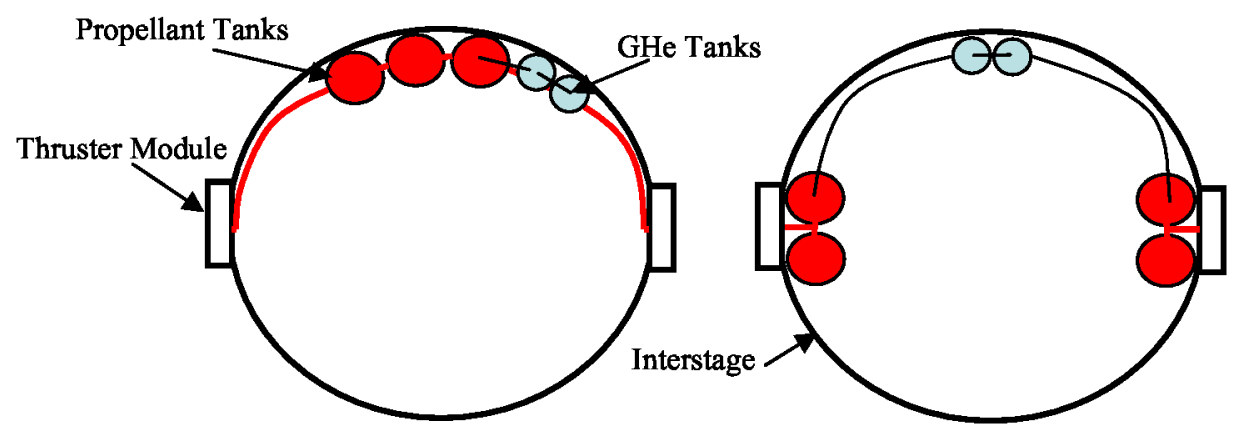

Figure 8. First Stage Roll Control System Schematic Representations of Distributed and Localized Propellant Tank Layouts.

The baseline architecture at the start of the trade study was a distributed architecture. The pressurant tanks were not considered for a localized tank layout as that would require an additional set of pressurization hardware (isolation valves, regulators, relief valves, etc). Relative to waterhammer mitigation, the localized propellant tanks allowed for much shorter propellant line runs to the thrusters, which decreased the propellant momentum stopped by the thruster valves and, thus, were the magnitude of the waterhammer surge pressures. Additionally, the propellant line diameters were increased to further reduce the propellant velocity and potentially justify the removal of the surge arrestors. The resulting line diameters necessary to warrant the removal of the surge arrestors was ultimately determined to be too large and bulky and would required added complexity to the hardware as the result, the surge arrestors were retained in the baseline architecture. Considering the FOMs of safety, reliability, mass, ground operations, power and avionics, and cost, the baseline architecture was changed to a localized tank configuration. The primary advantages for the localized tank configuration were lower waterhammer surge pressures (and consequently MDP), improved produceability, smaller propellant tanks (which provides additional separation and J2-X flyout zone clearance), and reduced vibration levels to thruster module components by the increase of localized mass at the thruster modules. The primary disadvantages to the localized configuration included additional complexity to propellant loading, decreased the availability of half of the propellant to each thruster module for a contingency scenario, and a slight mass increase.

\section{Thruster Module Design}

As noted earlier, one of the most significant design challenges for the Ares I RoCS and ReCS are the anticipated vibration environments. The monopropellant $\mathrm{N}_{2} \mathrm{H}_{4}$ thrusters present a difficult challenge to system design, as the catalysts that are used to decompose the $\mathrm{N}_{2} \mathrm{H}_{4}$, which are typically very brittle, are sensitive to high vibration levels. In addition to the high vibro-acoustic levels, the FS RoCS capability includes simultaneously meeting performance requirements under the additional loads of hot fire operation. With the combined high flowrate / high thrust class, high vibro-acoustic levels, and the necessity to operate the thrusters during the most severe anticipated environments, the FS RoCS has a fairly unique set of operating and design requirements. The major design areas and drivers for the thruster module were: waterhammer mitigation, minimization of structural loads to the thruster valve inlets, vibration isolation of the thrusters, minimization/reduction of the thruster module cross-sectional area (relative to the free stream), fairing shape and material selection, and thermal closeout from the nozzles to the fairing.

\section{Thruster Module Vibration Isolation and Propellant Manifold Design}

Early structural analysis based on the high vibration environments $\left(\sim 25 \mathrm{G}_{\mathrm{rms}}\right)$ indicated that some form of vibration isolation is necessary to protect the thruster catalyst bed from exceeding the maximum vibration levels that the intended design had experienced in previous programs (i.e., minimal test and flight heritage for the catalyst bed design at the anticipated unisolated vibration levels). At the Ares I RCS PDR, the RoCS thrusters were designed to include rubber grommet-style vibration isolators at the thruster to thruster mount structure interface. The vibration isolators were sized to shift the incoming external vibration environments (via the thruster mounts, thruster valve inlet, and nozzle to fairing closeout) to lower frequencies to move the primary acoustic modes outside of the region of concern for the catalyst. In order not to short circuit the vibration isolators it was necessary to minimize the loads 
transmitted to the thruster through both the thruster valve inlet as well as the thruster to fairing closeout (details of which will be discussed below). At the PDR, the propellant manifold design therefore incorporated flexlines from the main manifold trunk line to the thruster valve inlets. Figure 9 details the thruster module design at the time of the RCS PDR.

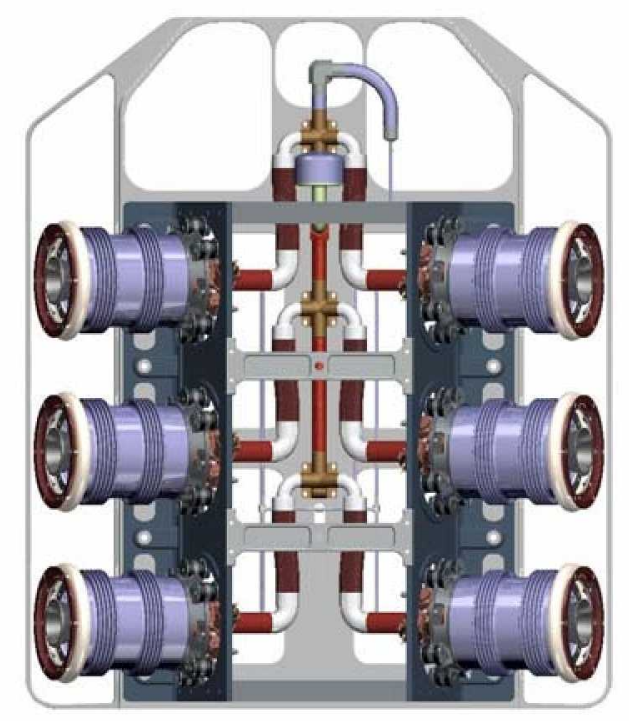

Figure 9. First Stage Roll Control System Thruster Module Layout at Preliminary Design Review.

Subsequent analysis post-PDR indicated that there were several issues that would require a redesign of the propellant manifold and thruster vibration isolation approach. The key issues with the PDR design were: excessive loads at the thruster valve inlet due to expansion of the inlet flexlines, short circuiting of the vibration isolators (also due to excessive inlet line loads), inability to drain propellant inlet lines, and increased thruster module width (which affects drag and support structure mass) to encompass manifold layout. A follow on trade study was conducted to address issues from PDR and provide additional design maturity.

The propellant manifold configurations considered for this trade included a "block" manifold and a "split" manifold design. The block manifold design consisted of a one-piece manifold machined out of a single block of metal, which includes six ports for each of the thrusters. Each thruster is mechanically attached perpendicular to the block manifold via individual thruster valve inlet ports and are fastened together using mating flanges with redundant seals. In addition, the vibration isolators are relocated from the individual thruster mount location to isolation between the thruster support structure and the baseplate. The split manifold design consists of the main propellant manifold being split into two parallel legs to individually feed three thrusters on each side of the thruster module. The two propellant lines combine together outside of the thruster module with compliance in each leg of the split manifold being provided with flexlines. In this configuration, vibration isolators are moved from the individual thruster mounts to isolation between the thruster mounting plates on either side of the module and the main thrust mount support structure. The split manifold design also incorporates an all-welded approach. Finally, any locations that are mechanically sealed require redundant, independently verifiable seals. Representations of the two manifold design concepts are shown in Figure 10. 


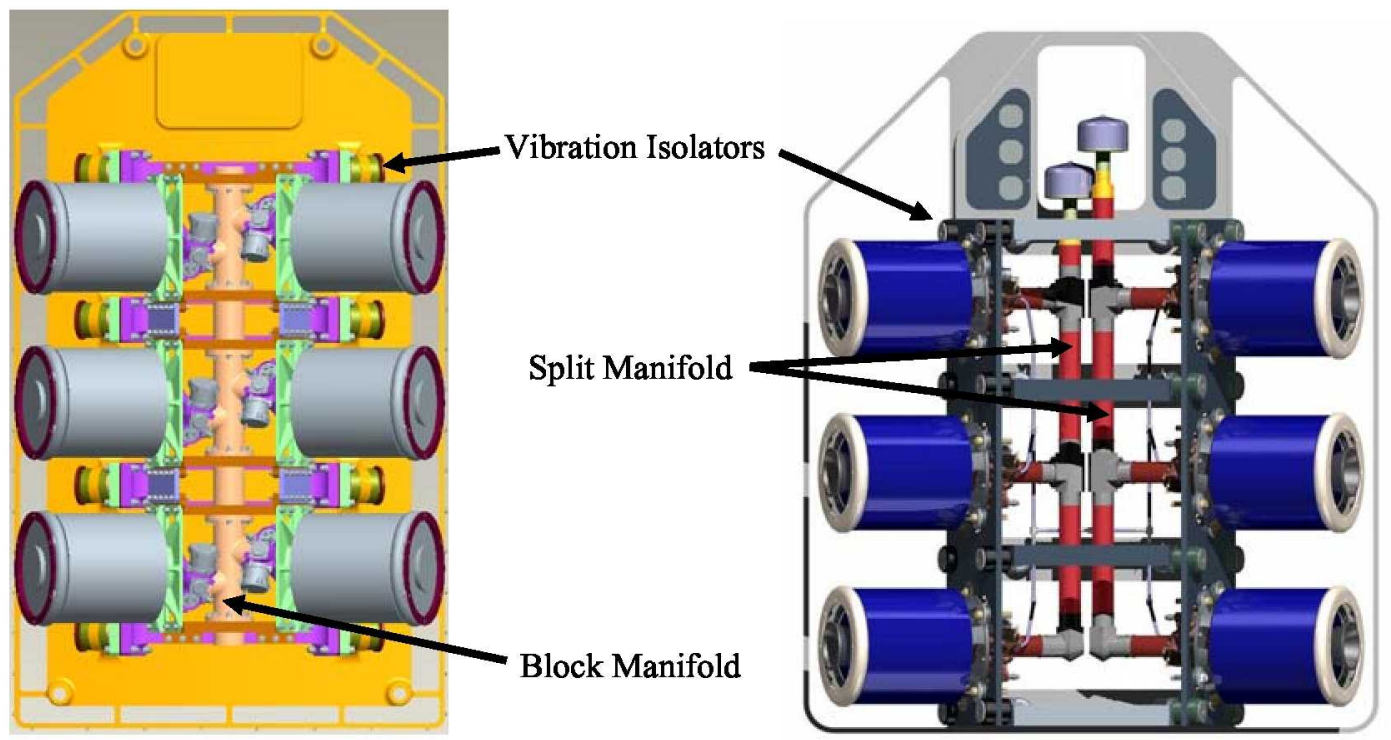

Figure 10. Block (left) and Split (right) Manifold Design Concepts.

Analysis results from system fluid dynamic models indicated reduced maximum waterhammer surge pressure levels for both design concepts (as compared to the PDR baseline), with a slight advantage to the block manifold design largely due to increased manifold diameter (2" vs. 1.5"). A vibration analysis was also conducted for each design. The block manifold results indicated that available off-the-shelf isolators would not provide adequate stiffness and support. As a result an increased quantity or, more likely an alternate type of isolator design was required, which would increase the cost, mass, envelope, and isolation design risk of the thruster module. Results for the split manifold design indicated that off-the-shelf isolators was required to mitigate vibration levels to acceptable levels. Both configurations significantly reduced inlet line loads.

The FOMs used to compare the two alternate configurations included: mass, envelope, number of seals, maximum expected waterhammer pressures, complexity of vibration isolation approach, produceability assessment, resulting fairing cross-sectional area, and a relative safety assessment. The trade study results recommended the split manifold design with the following rationale:

- Lower mass.

- No seals, much shorter time required for verification.

- Comparable waterhammer results to the block manifold, (both lower than PDR configuration).

- Vibration isolation possible with existing, off-the-shelf hardware.

- Produceability assessment indicated approximately half the hours as compared to the block manifold design for build up and assembly.

- No additional safety concerns related to independently verifiable, redundant seals i.e. all welded design.

Due to increased vibration loads and preliminary test data indicating that the flex line-based split manifold design may not provide adequate vibration isolation, an additional alternate thruster module manifold configuration trade study is underway. Preliminary representations of the primary configuration candidates are shown below in Figure 11. 

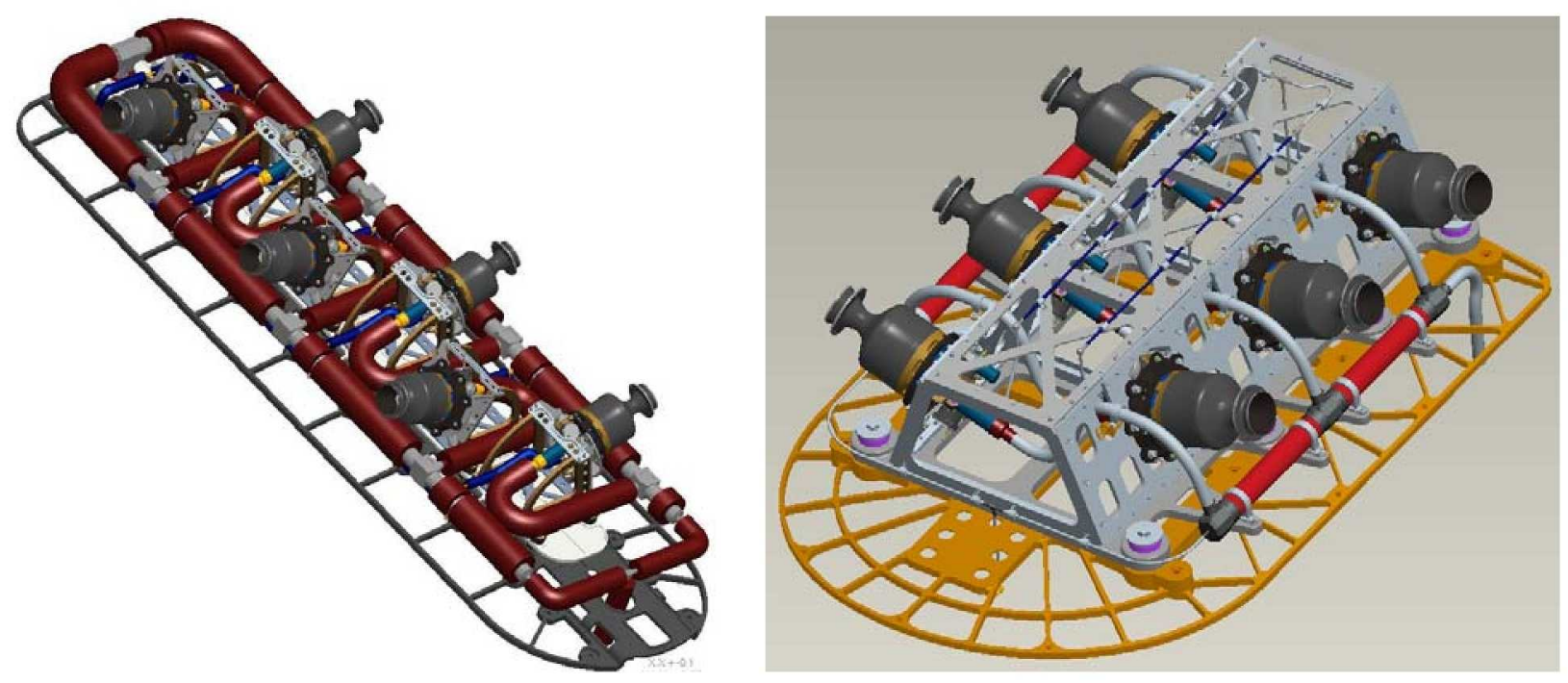

Figure 11. Preliminary Thruster Module Manifold Computer Aided Design Model Concepts.

\section{Thruster Closeout Design}

The design of the thruster to fairing closeout was determined early on as a challenging issue for the Ares I US ReCS and FS RoCS. The primary function of the closeout is to prevent any thermal, in-flight aerodynamic, or natural environments external to the thruster modules from entering into the thruster module via the annular gap surrounding the nozzle. The former of these could cause internal structures and $\mathrm{N}_{2} \mathrm{H}_{4}$ wetted items to exceed maximum temperature limits $\left(120^{\circ} \mathrm{F}\right.$ maximum for fairing thruster mounting structure and from $120^{\circ} \mathrm{F}$ to $200{ }^{\circ} \mathrm{F}$ for the $\mathrm{N}_{2} \mathrm{H}_{4}$ system, depending on mission phase). However, due to the severe vibration environments predicted for the Ares I ReCS and RoCS, an added complexity to the closeout design is that it must also be structurally compliant so as not to transmit aero-acoustic vibrations of the fairing to the catalyst bed (via the nozzle). This is important as the vibration isolators require relative motion of the thrusters from the fairing in order not to short out. Preliminary analysis indicates that the deflections could be up to 0.5 inches at the nozzle exit plane. The design criteria that were established to guide the design of the thruster closeout included:

- Must function as a thermal barrier - must be capable of limiting heat flux transmission from the exterior of the thruster module to the interior, such that the hardware temperature limits are not exceeded, and must do so while withstanding anticipated vibration, thermal, deflection, and pressure environments.

- Must minimize vibration and load transmission through the closeout hardware.

- Must allow for final assembly external to the thruster module - allows verification of individual barrier integrity prior to final closeout, and simplifies alignment issues.

- Must minimize number of parts, complexity, and mass.

A series of conceptual design approaches for the closeout were developed. Of these, two designs were collaboratively deemed most applicable and were selected for a detailed trade study. The first design was based on the Space Shuttle Forward Reaction Control System (FRCS) heritage sliding seal approach, which incorporates a compressive fit compliant barrier made out of a composite sandwich of a high temperature silica fabric and alumina stuffing. This design relies on a metallic insert which is placed into the fairing cutout and functions to both retain the thermal barrier as well as provide an opposing surface to the nozzle external wall which the barrier can compressively seal against. The second design concept was based in part on the environmental closeout curtains with heritage to various Main Propulsion System (MPS) engines, such as the Space Shuttle Main Engine and the Delta IV RS-68. The basic design concept is that an inner ring (which attaches to the nozzle) and an outer ring (which attaches to the fairing) retain a compliant, fabric-like thermal curtain which serves to inhibit external heat fluxes from entering the thruster module and greatly reduce the load path from the fairing to the nozzle. The compliant thermal curtain would also be sized to allow worst case relative motion of the fairing and the nozzle without short-circuiting the vibration isolators. Conceptual CAD models for each of the two design approaches are shown in Figure 12. 

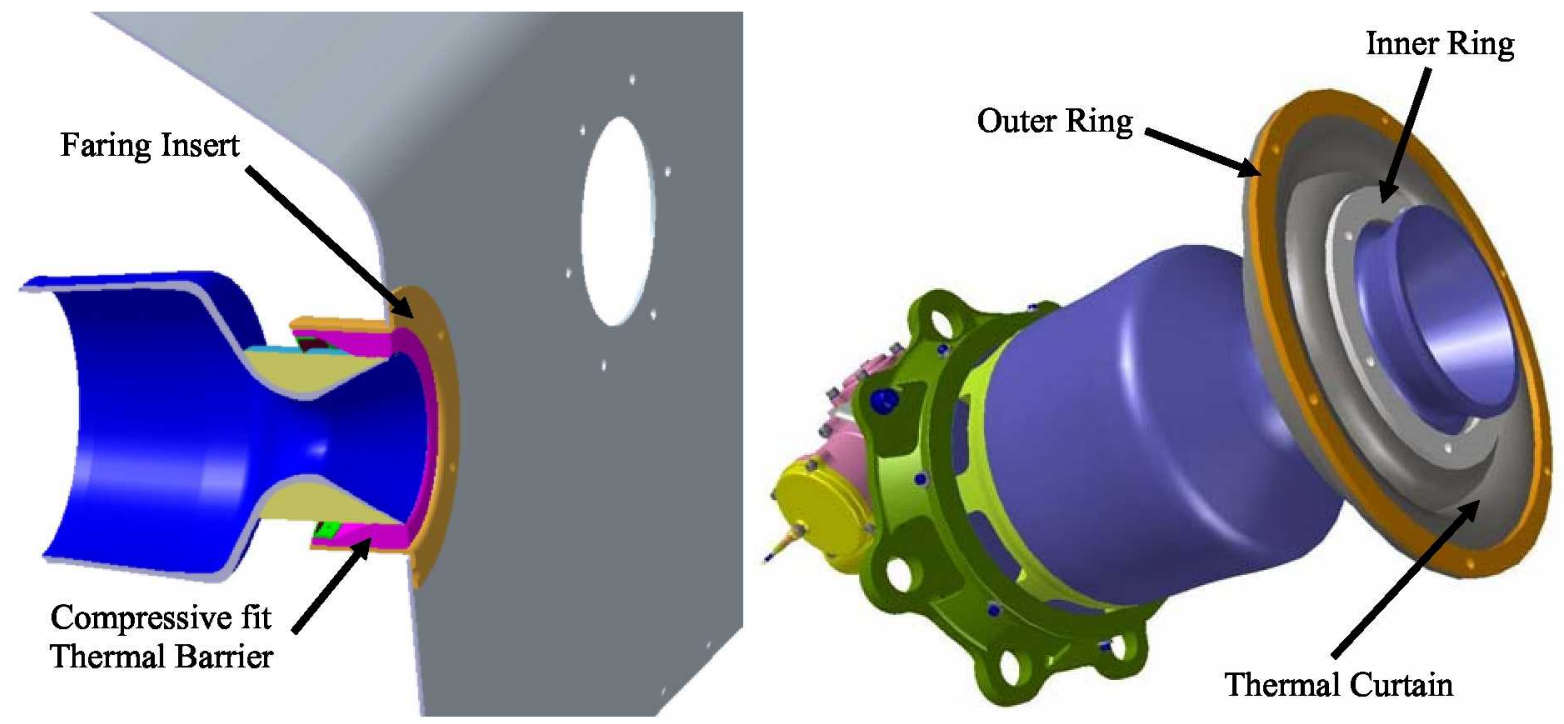

Figure 12. Conceptual Space Shuttle FRCS-Style Thruster Closeout Model (left) and Thermal Curtain Closeout Model (right), Shown using First Stage Roll Control System Thruster.

The FOMs used to compare (relatively) these two designs included (in order of importance):

- Preclusion of hot gas entry into the thruster module.

- Transmission of dynamic excitation to the catalyst bed.

- Minimization of conductive heat transfer to the fairing.

- Minimization of radial and axial forces imparted on the nozzle.

- Ease of installation.

- Design heritage.

- Manufacturability.

- Mass.

- Schedule and cost risk.

The recommendation of the trade study was to pursue the thermal curtain design approach. The main rationale included:

- Depending on thickness and type of seal material, and due to compressive fit design, under radial nozzle deflections, seal material may lose compression and allow additional leakage for the Space Shuttle FRCS-style closeout as compare to the more compliant thermal curtain design.

- Minimizes the transmission of dynamic excitation to the catalyst bed (due in large part to the thermal curtain not being a compressive style fit).

- Minimal forces imparted on the nozzle as compared to the Space Shuttle FRCS-style compressive fit barrier.

- Allows for complete final assembly external to the thruster module without the need to slide fit the barrier.

- No perceived differences as far as flight heritage since both approaches have similar design implementations on other flight vehicles.

- Lowest mass, easiest to produce, and lowest cost option.

\section{Upper Stage Reaction Control System}

\section{A. Mission Overview}

The initial operation of the US ReCS follows the separation of the FS element. Once the FS element separates, the US ReCS will provide three DOF pitch, yaw, and roll control for the US element until the J-2X reaches rated thrust. After J-2X engine ignition, only roll control will be provided by the US ReCS. Any induced pitch and yaw 
moments will be counteracted by the gimbaling of the J-2X engine. Three DOF control will also be provided by the US ReCS during US J-2X shutdown and coast periods leading up to the crewed vehicle separation.

\section{B. Subsystem Requirements}

The US ReCS configuration is a distributed monopropellant $\mathrm{N}_{2} \mathrm{H}_{4}$ blowdown propulsion system. It has two thruster modules $180^{\circ}$ apart on the outer diameter of the US Aft Skirt. US ReCS architecture includes pressurant loading and storage, propellant loading and storage, acquisition and delivery system, and thrusters. The thrusters utilize a catalyst bed with a $90^{\circ}$ turn flow nozzle for improved reliability and cost. They also are sized to meet the US ReCS impulse, moment, duty cycle, electric pulse width, impulse life, impulse bit, and thrust level requirements. This architecture provides one fault tolerance for function and one fault tolerance against catastrophic hazards during ground and flight operations.

The US ReCS operates for approximately eight minutes, following US element separation from the FS element. Nominal operation of the US ReCS occurs under various conditions experienced during the mission. These conditions include vibration/shock, hot environments, cold environments, and structural loads. Vibration and shock conditions occur throughout the non-operational and operational of the US ReCS. The most intense of these conditions is the shock generated during the separation of the US from the FS.

To properly function, the US ReCS must survive the expected vibration conditions which occur during launch and the FS element operational phase. The US ReCS is expected to experience potentially large temperature variations due to proximity of the cryogenic storage tanks of the US element MPS. The US ReCS is located in close proximity to the J-2X and during planned operation will be exposed to higher temperatures generated by the J-2X and its plume. The US ReCS propellant tank will also experience lower temperatures due to its current location on the thrust cone of the US element. The thrust cone is located on the aft dome of the Liquid Oxygen (LOX) tank. Finally, the US ReCS will be designed to handle the expected structural loads that will occur throughout the Ares I mission.

As with the FS RoCS, the US ReCS has been required by the CxP to encompass transient system pressures into system MDP. The current US ReCS pressure budget assumes the following:

- Propellant tank volume - 5,555 $\mathrm{in}^{3}$.

- Nominal pressurant load $-0.71 \mathrm{lbm}$ of GHe at $415 \mathrm{psia}$ and $120^{\circ} \mathrm{F}$.

- Pressurant loaded between $95^{\circ} \mathrm{F}$ and $120^{\circ} \mathrm{F}$.

- $\quad$ Flight temperature between $85^{\circ} \mathrm{F}$ and $95^{\circ} \mathrm{F}$.

- Pressure drop for a given component is scalable based on flow rate.

- Nominal pressure drop for components at $0.446 \mathrm{lbm} / \mathrm{sec}$ of $\mathrm{N}_{2} \mathrm{H}_{4}$ assuming four thrusters are firing.

- For a given number of thrusters firing it is assumed that each thruster receives an equal propellant flow rate.

Based on the current blowdown configuration and updated thruster performance data, the US ReCS and all associated components must be designed to perform over a range of propellant flow rates and pressures. The general pressure budget is established using two boundary scenarios since the US ReCS must perform over the following ranges:

- Highest initial performance or thrust:

- Beginning of mission $120 \mathrm{lbf}$ thrust based on GN\&C requirements.

- $0.72 \mathrm{lbm}$ GHe loaded (405 psia at $95^{\circ} \mathrm{F}$ ), flight temperature at $95^{\circ} \mathrm{F}$ and a propellant tank volume of $5,555 \mathrm{in}^{3}$.

- One thruster firing.

- Lowest final performance or thrust:

- End of mission $90 \mathrm{lbf}$ thrust based on GN\&C requirements.

○ $0.67 \mathrm{lbm}$ GHe loaded (393 psia at $120^{\circ} \mathrm{F}$ ), flight temperature at $85^{\circ} \mathrm{F}$ and a propellant tank volume of $5,555 \mathrm{in}^{3}$.

- Four thrusters firing.

The DAC-3A_S US ReCS pressure budget at the upper boundary condition is shown in Table 6, while the pressure budget at the lower boundary condition is shown in Table 7. For both conditions, nominal pressure drops from column one are defined with four thrusters firing at a vacuum rated thrust of $100 \mathrm{lbf}$ while the pressure drops in column two are scaled from the nominal pressure drops. 
Table 6. Upper Stage Reaction Control System Upper Boundary Condition Pressure Budget.

\begin{tabular}{|l|r|r|}
\hline Number of Thrusters Firing & 4 & 1 \\
\hline Tank Pressure (psia) & & $\mathbf{4 2 0}$ \\
\hline & & \\
\hline Tank Outlet (psid) & 8 & 0.7 \\
\hline Line Loss (psid) & 19 & 1.7 \\
\hline Flex Line (psid) & 3 & 0.3 \\
\hline Thruster Assembly Inlet Pressure (psia) & 320.4 & $\mathbf{4 1 7 . 4}$ \\
\hline Mass Flow Rate per Thruster (Ibm/sec) & 0.446 & 0.532 \\
\hline Vacuum Rated Thrust per Thruster (lbf) & 100 & 120 \\
\hline & & \\
\hline Tank MDP & & 550 \\
\hline Feed System MDP (psia) & & 1125 \\
\hline
\end{tabular}

Table 7. Upper Stage Reaction Control System Lower Boundary Condition Pressure Budget.

\begin{tabular}{|l|r|r|}
\hline Number of Thrusters Firing & 4 & 4 \\
\hline Tank Pressure (psia) & & 299 \\
\hline Tank Outlet (psid) & 8 & 6.5 \\
\hline Line Loss (psid) & 19 & 15.4 \\
\hline Flex Line (psid) & 3 & 2.4 \\
\hline Thruster Assembly Inlet Pressure (psia) & 320.4 & 274.4 \\
\hline Mass Flow Rate per Thruster (Ibm/sec) & 0.446 & 0.402 \\
\hline Vacuum Rated Thrust per Thruster (lbf) & 100 & 90 \\
\hline & & \\
\hline Tank MDP & & 550 \\
\hline Feed System MDP (psia) & & 1125 \\
\hline
\end{tabular}

The current flight power requirements for the US ReCS can be found in Table 8. These power estimates represent the maximum power consumption during operation. 
Table 8. Upper Stage Reaction Control System Flight Power Requirements.

\begin{tabular}{|c|c|c|c|c|c|}
\hline Component & US Total & $\begin{array}{c}\text { US Max } \\
\text { During } \\
\text { Operation }\end{array}$ & $\begin{array}{c}\text { Estimated Peak } \\
\text { Current } \\
\text { Required (Amps) }\end{array}$ & $\begin{array}{c}\text { Estimated Peak } \\
\text { Power Required } \\
\text { (Watts) }\end{array}$ & $\begin{array}{c}\text { Estimated } \\
\text { operation } \\
\text { time at } \\
\text { peak draw } \\
\text { (seconds) }\end{array}$ \\
\hline Temperature Transducers & 70 & 70 & 0.07 & 1.96 & 683.9 \\
\hline Pressure Transducers & 14 & 14 & 0.420 & 11.76 & 683.9 \\
\hline $\begin{array}{c}\text { Serial Solenoid Valve } \\
\text { (Thruster Control Valves) }\end{array}$ & 24 & 8 & 16.00 & 448.00 & 20.5 \\
\hline Catalyst Bed Heaters & 24 & 12 & 3.50 & 84.00 & 683.9 \\
\hline Total & & & & $\mathbf{5 4 5 . 7 2}$ & \\
\hline
\end{tabular}

For the serial solenoid valves (thruster control valves), these values assume eight valves are actuated, so four thrusters would be firing simultaneously. There exists enough fuel for approximately $82 \mathrm{sec}$ of run time using 30 $\mathrm{lbm}$ of usable propellant and the mass flow rate for one thruster. Because the US ReCS is a blowdown propulsion system, the flow rate varies with temperature and the actual number of thrusters firing. Also, the serial solenoid valves (thruster control valves) operation time at peak draw of $20.5 \mathrm{sec}$ includes a $10 \%$ overhead factor to account for the possibility of a slightly longer thruster burn time. The US element operational duration is $586.2 \mathrm{sec}$ with an active mission duration of 459.9 sec.

During every revision of a DAC, the mass properties of the US ReCS have been updated and maintained. These mass properties have increased in fidelity as the design of the US ReCS has matured. Currently, each US ReCS mass properties table contains dry mass information about structure, propellant tank, components, miscellaneous items, and thrusters. They also contain wet mass information about consumables, i.e. GHe pressurant, ascent propellant, and residual propellant.

The current baseline is the DAC-3A_S_RevB US ReCS mass properties. This current revision of the US ReCS mass properties are found in Table 9 and represents multiple changes. Recent updates include relocating a majority of the propellant tubing from the thrust cone to the aft skirt on the US element. As a result, the fidelity of many structural components have increased, leading to a total US ReCS mass without Mass Growth Allowance (MGA) of $477.7 \mathrm{lbm}$. With MGA the US ReCS currently weighs $517.0 \mathrm{lbm}$. 
Table 9. Design Analysis Cycle -3A_Start_Revision B Upper Stage Reaction Control System Mass Properties Rollup.

\begin{tabular}{|l|c|c|}
\hline US ReCS Mass Properties Rollup & $(\mathbf{l b m}, \mathbf{w} / \mathbf{0}$ MGA) & $(\mathbf{l b m}, \mathbf{w}$ MGA) \\
\hline \multicolumn{1}{|c|}{ Dry Mass } & & \\
\hline (I.) Structure & 209.7 & 227.9 \\
\hline (II.) Propellant Tank & 32.0 & 34.6 \\
\hline (III. \& IV.) Components & 113.0 & 125.1 \\
\hline (V.) Thrusters & 78.4 & 84.9 \\
\hline Total Dry Mass & 433.1 & 472.4 \\
\hline Wet Mass & & \\
\hline (VI.) Consumables & & \\
\hline A. GHe Pressurant & 1.0 & 1.0 \\
\hline B. Ascent Propellant & 30.0 & 30.0 \\
\hline C. Residual Propellant & 13.6 & 13.6 \\
\hline Total Wet Mass & 44.6 & 44.6 \\
\hline Total US ReCS Mass & $\mathbf{4 7 7 . 7}$ & $\mathbf{5 1 7 . 0}$ \\
\hline
\end{tabular}

Throughout the design of the US ReCS, the functional schematic has gone through multiple revisions. The current version is the DAC-3A_S_RevA US ReCS functional schematic key and schematic, which are shown in Figure 13 and Figure 14. The DAC-3A_S_RevA US ReCS functional schematic reflects a distributed monopropellant blowdown propulsion system with numbered $120 \mathrm{lbf}$ three DOF pitch, yaw, and roll control thrusters. All components that are currently in the US ReCS can be found in the DAC-3A_S_RevA US ReCS functional schematic key. The key also provides the name and symbol of every component used in the DAC3A_S_RevA US ReCS functional schematic.

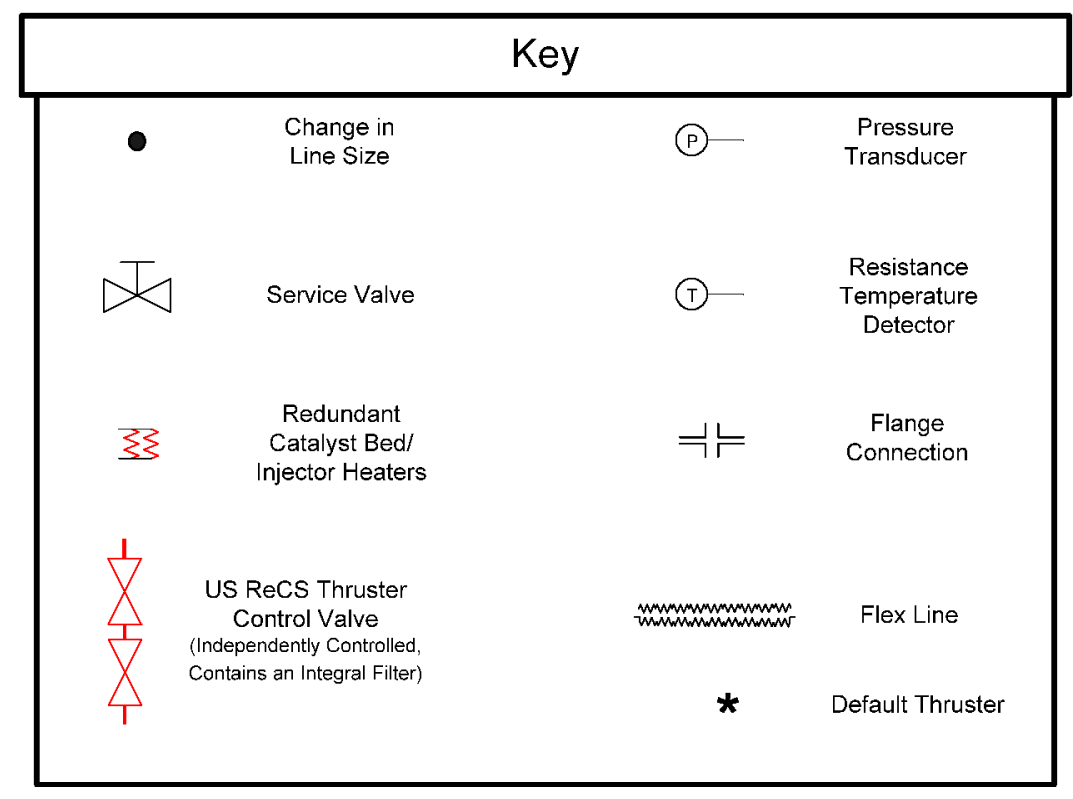

Figure 13. Design Analysis Cycle - 3A_Start_Revision A Upper Stage Reaction Control System Functional Schematic Key. 


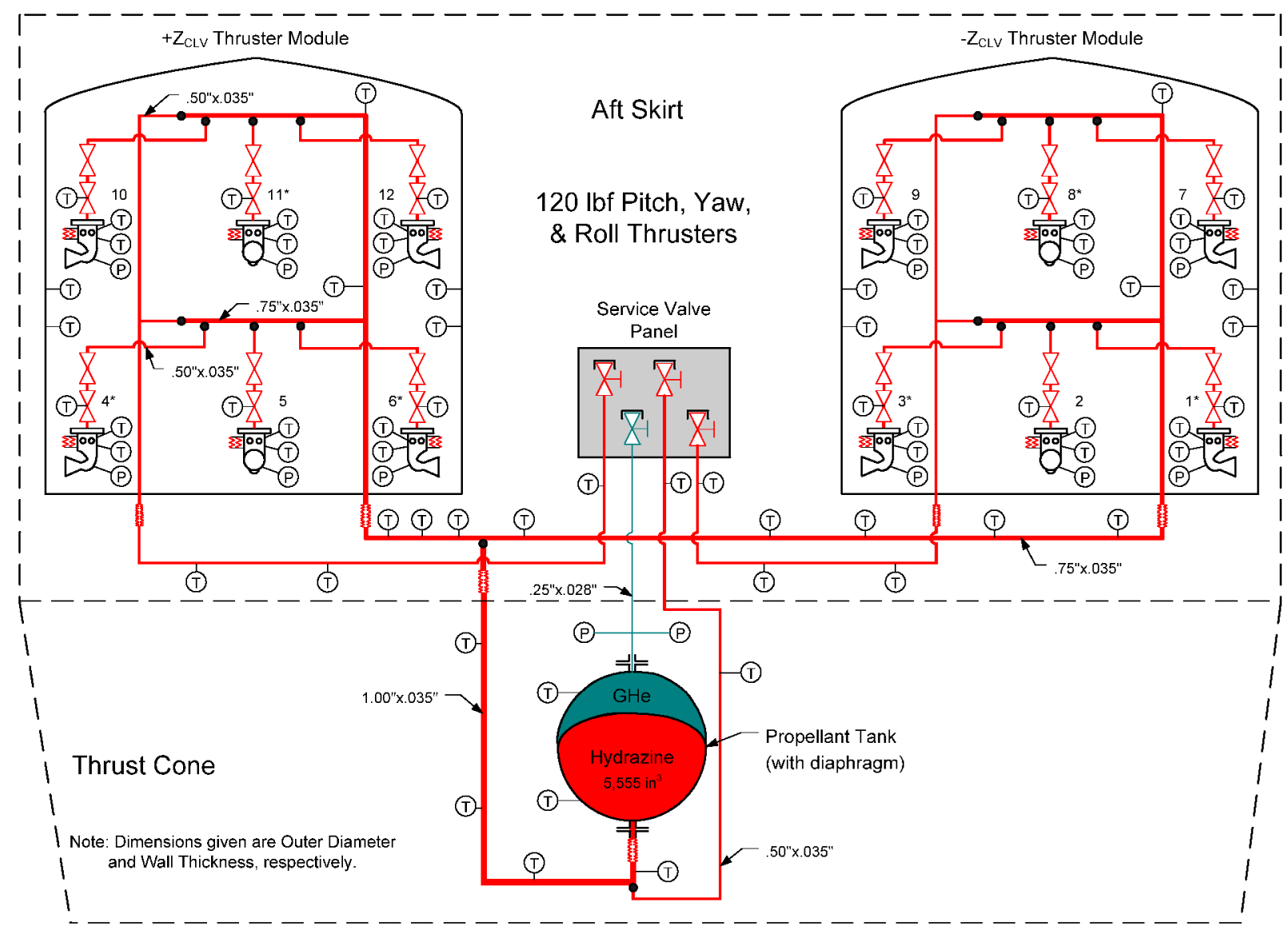

Figure 14. Design Analysis Cycle-3A_Start_Revision A Upper Stage Reaction Control System Schematic.

CAD models have been developed for the US ReCS throughout its design. Currently, the service valve panel, thruster modules, and a majority of the propellant tubing are located on the aft skirt of the US element. The propellant tank is attached to the thrust cone, which is mounted on the aft end of the LOX dome. The current US ReCS flight configuration, as shown in Figure 15, consists of two thruster modules, propellant tank, service valve panel, mounting hardware, tubing, insulation and associated components.

At PDR, a majority of the US ReCS propellant tubing was mounted on the thrust cone. After PDR, the majority of the tubing was relocated to the aft skirt due to thermal issues with the aft end of the LOX dome and available thrust cone space. The thermal issues associated with the aft end of the LOX dome were related to cold conditioned ground purges. This relocation led to the rerouting of the propellant tubing where new interference issues with other subsystems, such as avionics boxes and the environmental control system purge tubing, were encountered on the aft skirt. These issues have been worked and partially resolved with the resulting configuration now reflected in the current CAD models and schematic. A picture of the US ReCS propellant tank assembly CAD model is shown in Figure 16. From that picture the propellant tank flange connections, support struts, tubing, insulation, and line support brackets can also be seen. Finally, Figure 17 provides a top and side view of the current thruster module without insulation on the outside surface of the fairing or around each individual thruster. 


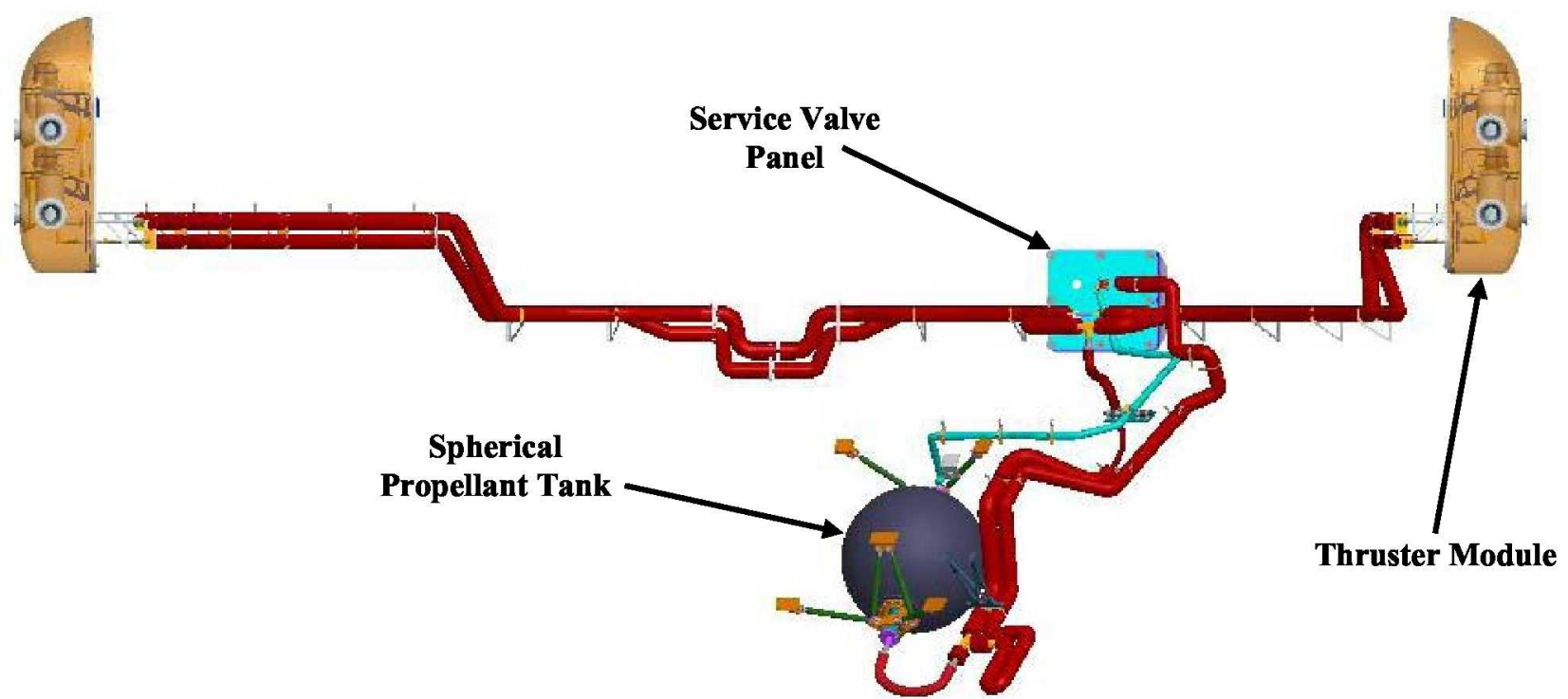

Figure 15. Upper Stage Reaction Control System Flight Configuration Computer Aided Design Model.

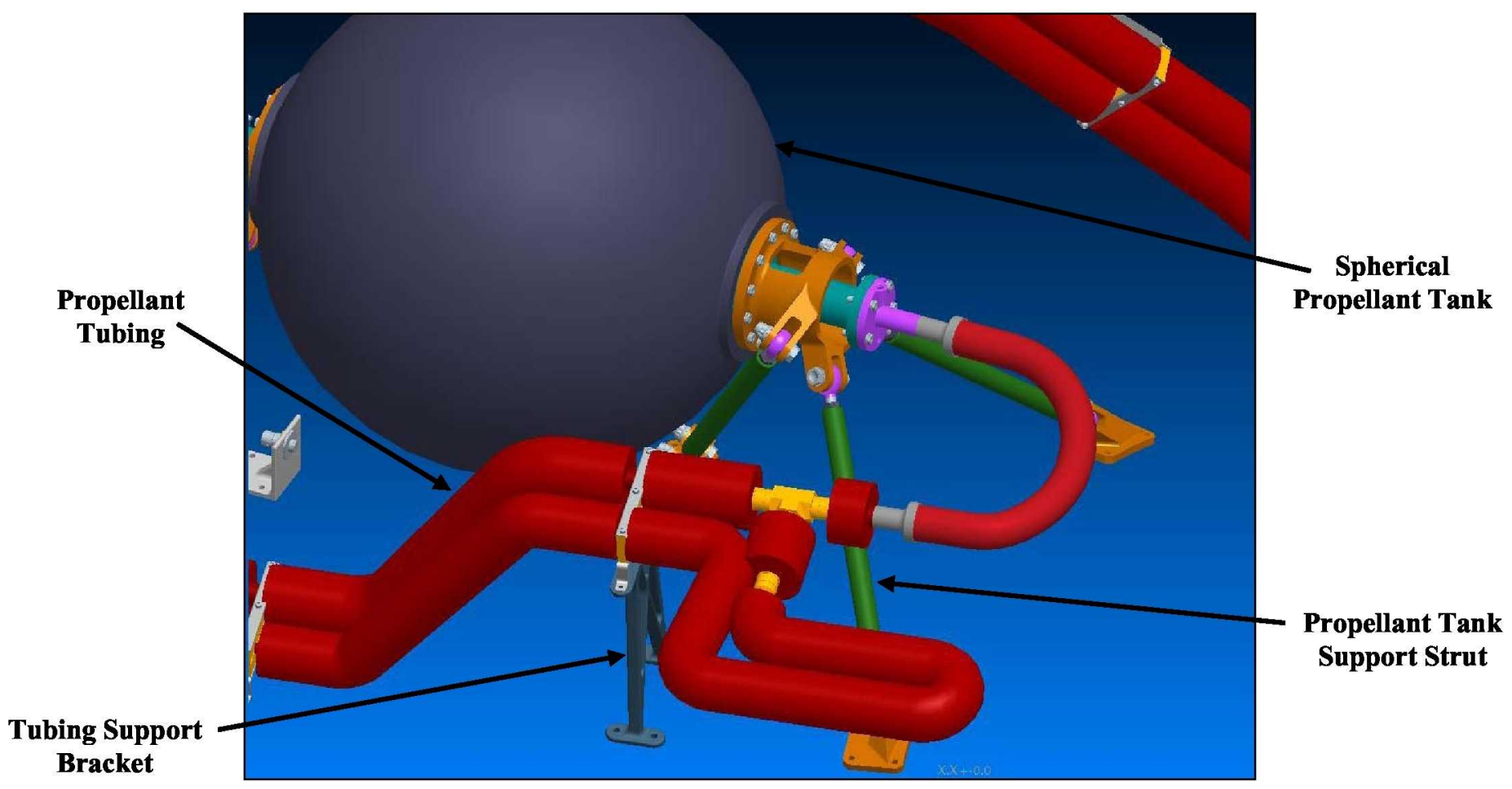

Figure 16. Upper Stage Reaction Control System Propellant Tank Assembly Computer Aided Design Model. 

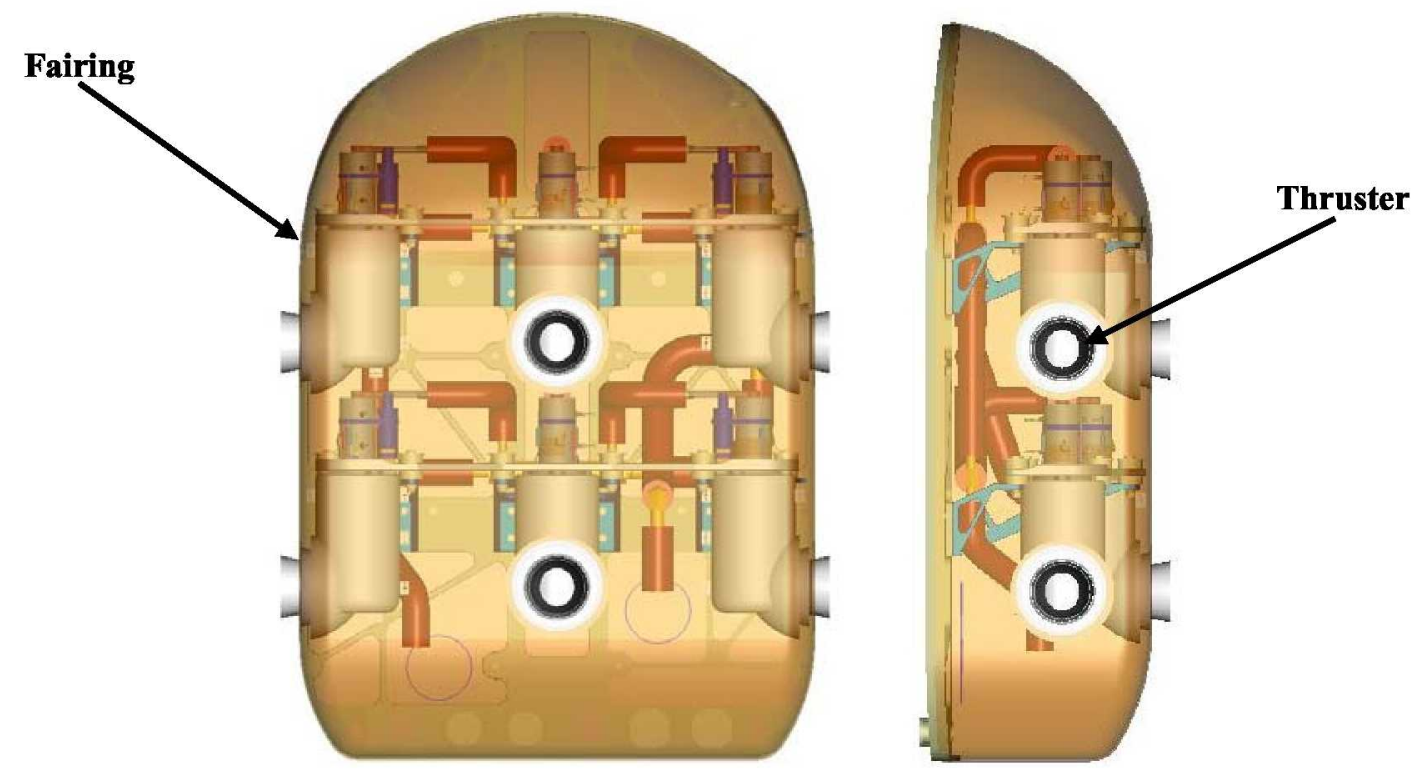

Figure 17. Upper Stage Reaction Control System Thruster Module Computer Aided Design Model.

To fully understand the physical size of the US ReCS a few of its basic dimensions are found in Table 10 . The basic dimensions include the outer diameter of the propellant tank, the size of the thruster module, and the distance between the propellant tank and each thruster module. Also, all dimensions are based on the current version of the US ReCS CAD model.

Table 10. Basic Dimensions for the Upper Stage Reaction Control System Flight Configuration.

\begin{tabular}{|l|l|}
\hline \multicolumn{2}{|c|}{ Upper Stage Reaction Control System Basic Dimensions } \\
\hline Tank & \\
\hline Spherical Metal Tank & $22.3^{\prime \prime}$ OD \\
\hline Thruster Module & \\
\hline Height & $41.3^{\prime \prime}$ \\
\hline Width & $28.3^{\prime \prime}$ \\
\hline Depth & $12.3^{\prime \prime}$ \\
\hline Approximate Line Lengths & \\
\hline Tank to $+Z_{\mathrm{CLV}}$ Thruster Module & $212.6^{\prime \prime}$ \\
\hline Tank to - $Z_{\mathrm{CLV}}$ Thruster Module & $341.3^{\prime \prime}$ \\
\hline
\end{tabular}

\section{Propulsion System Design Assessments and Trade Studies}

Through an iterative process of design assessments and trade studies, the RCS NDT has attempted to simplify, reduce the risk, and optimize the US ReCS. The simplification of the US ReCS by the RCS NDT has driven the system towards a more reliable and robust design. The US ReCS trades accomplished so far have allowed the design to drive towards maturity and optimization. The following US ReCS system trades have been conducted: propellant selection, thruster arrangements, valve arrangements, pressurization system (blowdown vs. regulated), and distributed verses pod architecture.

\section{Propellant Selection}

Two propellant combinations for the US ReCS were compared, based on the subsequent systems needs for each to meet the mission requirements. The two combinations of propellants traded were monopropellant $\mathrm{N}_{2} \mathrm{H}_{4}$ and bipropellant MMH and NTO. A monopropellant $\mathrm{N}_{2} \mathrm{H}_{4}$ propulsion system can supply an $\mathrm{I}_{\text {sp }}$ around 225 sec and pulsing or steady state thrust ranging from $0.1 \mathrm{lbf}$ to several hundred pound force. A bipropellant propulsion system 
is very versatile and high performing, supplying an $I_{\mathrm{sp}}$ of about $310 \mathrm{sec}$ and a wide range of pulsing or steady state thrust capability (from a few pounds to many thousands of pounds). At the end of DAC-1C, it was determined that the US ReCS could be modified to a monopropellant architecture and still meet the US system requirements. This architectural change reduced the complexity of the US ReCS, and provided additional benefits, such as simplified propellant loading at the launch pad.

\section{System Architecture}

A pressurization system trade study was conducted to compare a regulated system to a blowdown system which resulted in an optimal configuration for the pressurization system of the US ReCS. A mechanical regulator controls the pressure of a propulsion system by using a pressurizing gas stored at a preset pressure in a tank or tanks. The pressurizing gas (pressurant) is stored at a high pressure, usually $3,000-5000 \mathrm{psi}$, and then is mechanically throttled to a lower pressure band. This lower pressure drives propellant from the tank or tanks towards the thrusters. From the beginning of DAC-1A to the end of DAC-1C, the US ReCS has had a regulated pressurization system as shown in Figure 18.

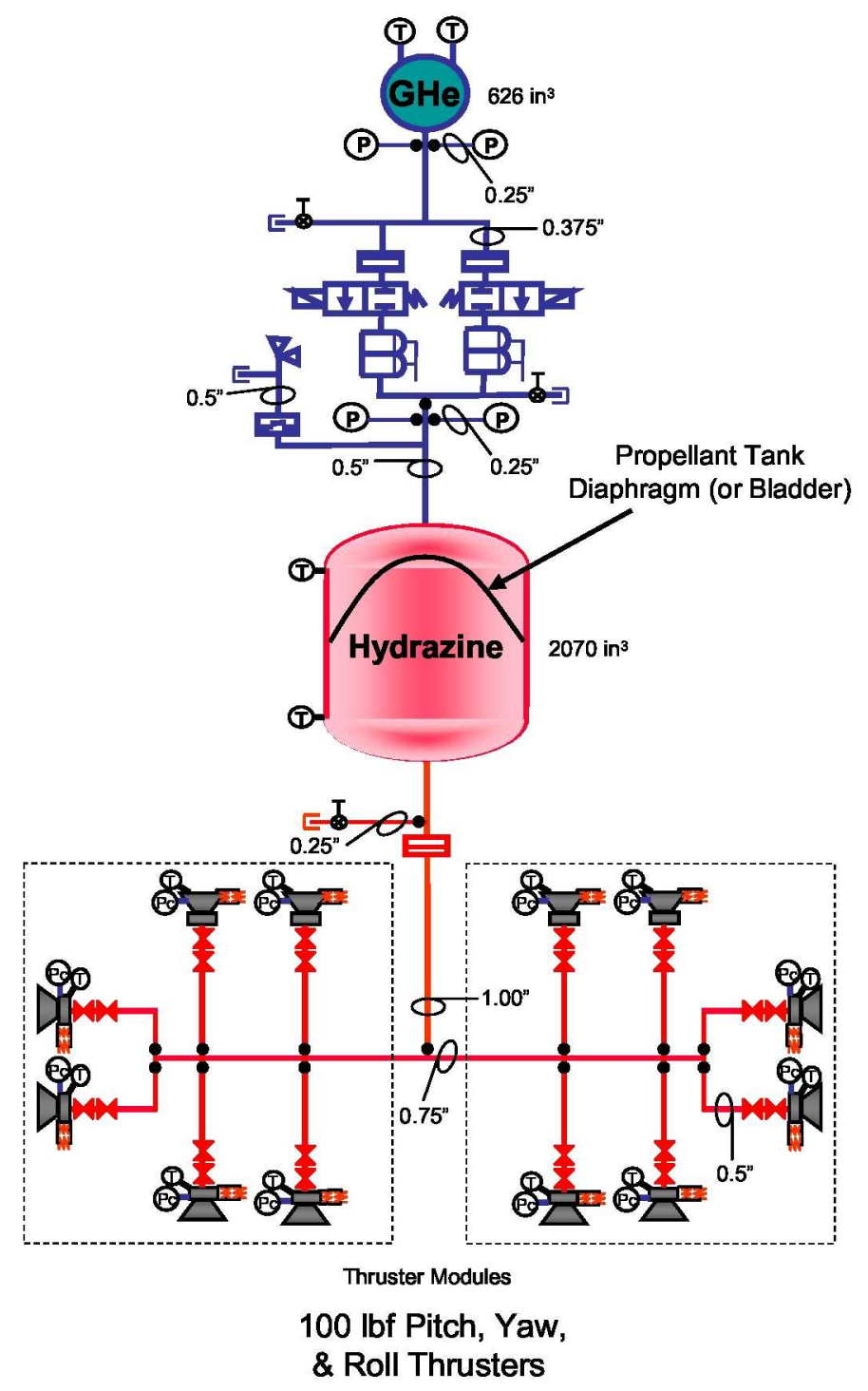

Figure 18. Design Analysis Cycle-1C_Exit Upper Stage Reaction Control System Schematic.

The pressure regulated subsystem consists of a GHe pressurant tank, filters, isolation valves, regulators, burst disk, relief valve, and pressurant lines. The primary advantage of a pressure regulated subsystem is constant thrust as a function of time. 
For a blowdown propulsion system, a propellant tank is pressurized to an initial level, and the pressure is allowed to decay as propellant is used. The disadvantages of a blowdown propulsion system include variances with tank pressure, thrust, and propellant flow rate as a function of time along with a larger propellant tank volume. Also, the $I_{s p}$ is a second order function of chamber pressure for monopropellant propulsion systems and drops as a function of time. Blowdown propulsion systems do provide advantages in that they are typically more simple, reliable, and cheaper that a regulated system. At the beginning of DAC-2A, it was determined and agreed upon with GN\&C that the variation in thrust due to the blowdown system was acceptable for the mission life of the US ReCS. The Design Analysis Cycle -2A_Start (DAC-2A_S) US ReCS schematic is shown in Figure 19.

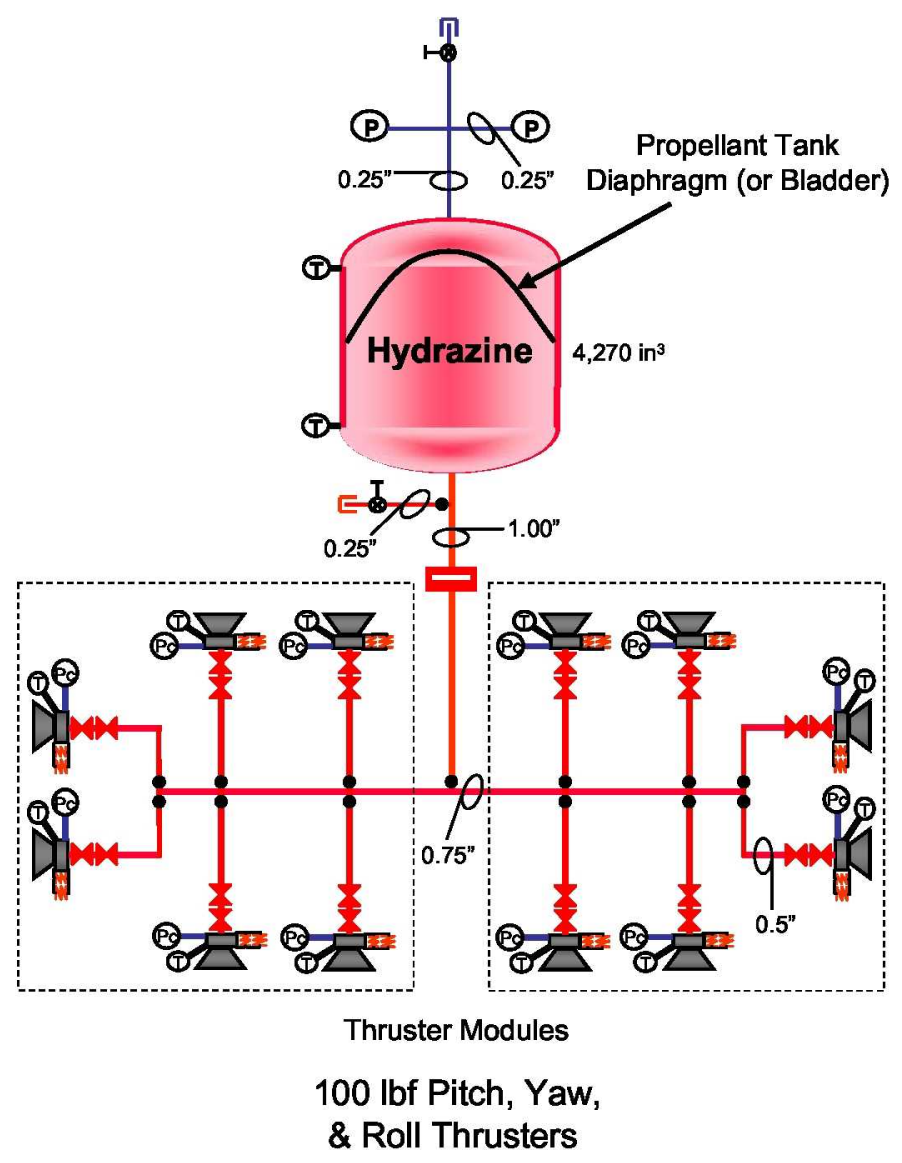

Figure 19. Design Analysis Cycle - 2A_Start Upper Stage Reaction Control System Schematic.

\section{Thruster Configuration}

Thruster configuration was assessed based on compactness and manufacturability, while also meeting the fault tolerance requirements. Fault tolerance requirements for the US ReCS consist of providing one backup thruster per thruster leg for each thruster module. Comparison of thruster arrangement options included mass, complexity, producibility, reliability, and redundancy.

One important consideration was the arrangement of thrusters whereby no thermal issues could occur due to plume interaction from adjacent thrusters. The extreme temperatures produced by the thrusters during operation could damage other components, possibly causing them to fail. Upon completion of the thruster arrangement trade study, it was determined that the thrusters would be arranged in a plus $(+)$ and minus $(-)$ pitch, yaw, and roll control configuration in each thruster module. During operation, a pair of thrusters per module would provide the yaw and roll function, while a third thruster would provide the pitch function. Completion of the assessment impacted the architecture of the US ReCS with regard to structure, layout, packaging, and aerodynamics. 


\section{Component/Valve Configuration}

To assure the desired thruster performance during operation the optimal valve configuration for the US ReCS had to be determined. Some valve characteristics considered were heritage, response time, operating pressure, and operating temperature. The Design Analysis Cycle - 1A_Exit (DAC-1A_E) US ReCS schematic is shown in Figure 20.

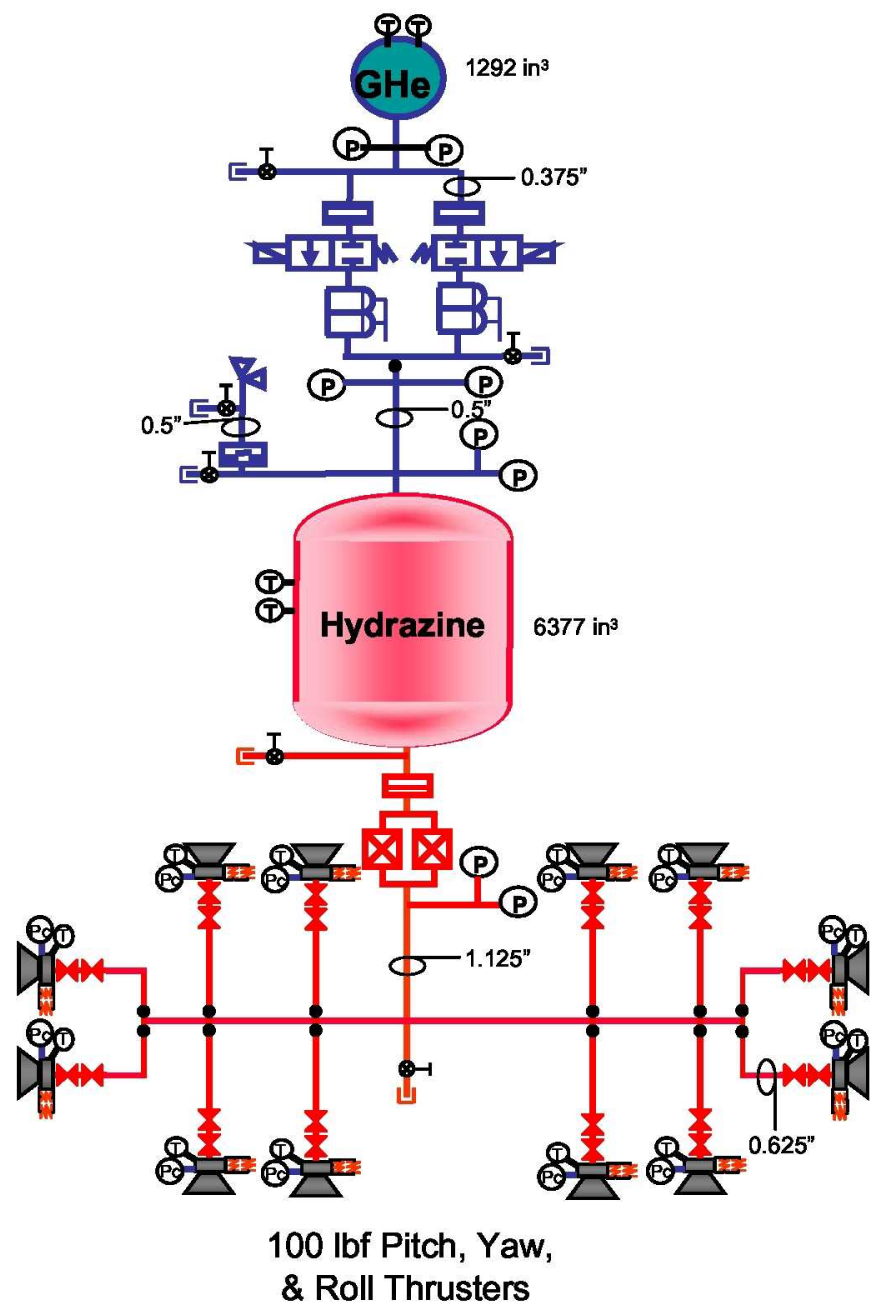

Figure 20. Design Analysis Cycle - 1A_Exit Upper Stage Reaction Control System Schematic.

The DAC-1A_E US ReCS schematic had two parallel propellant isolation valves, located on the propellant trunk line upstream of each thruster module. The primary reason for the propellant isolation valves was to meet the requirement for two fault tolerance against catastrophic hazards during ground operations. The location of the valves allowed the US ReCS the ability to isolate $\mathrm{N}_{2} \mathrm{H}_{4}$ in the propellant tank from thrusters in the ground environment.

During DAC-1B the two propellant isolation valves were traded against serial thruster valves. The serial thruster valves allowed isolation of individual thrusters, rather than the isolation of the entire thruster module. The serial thruster valves also had flight heritage, provided two barriers to inadvertent thruster firing, and operated independently of one another. At DAC-1B_E, the serial thruster valves were chosen, based on redundancy, fault tolerance, and control of individual thrusters in the US ReCS. The DAC-1B_E US ReCS schematic is shown in Figure 21. 


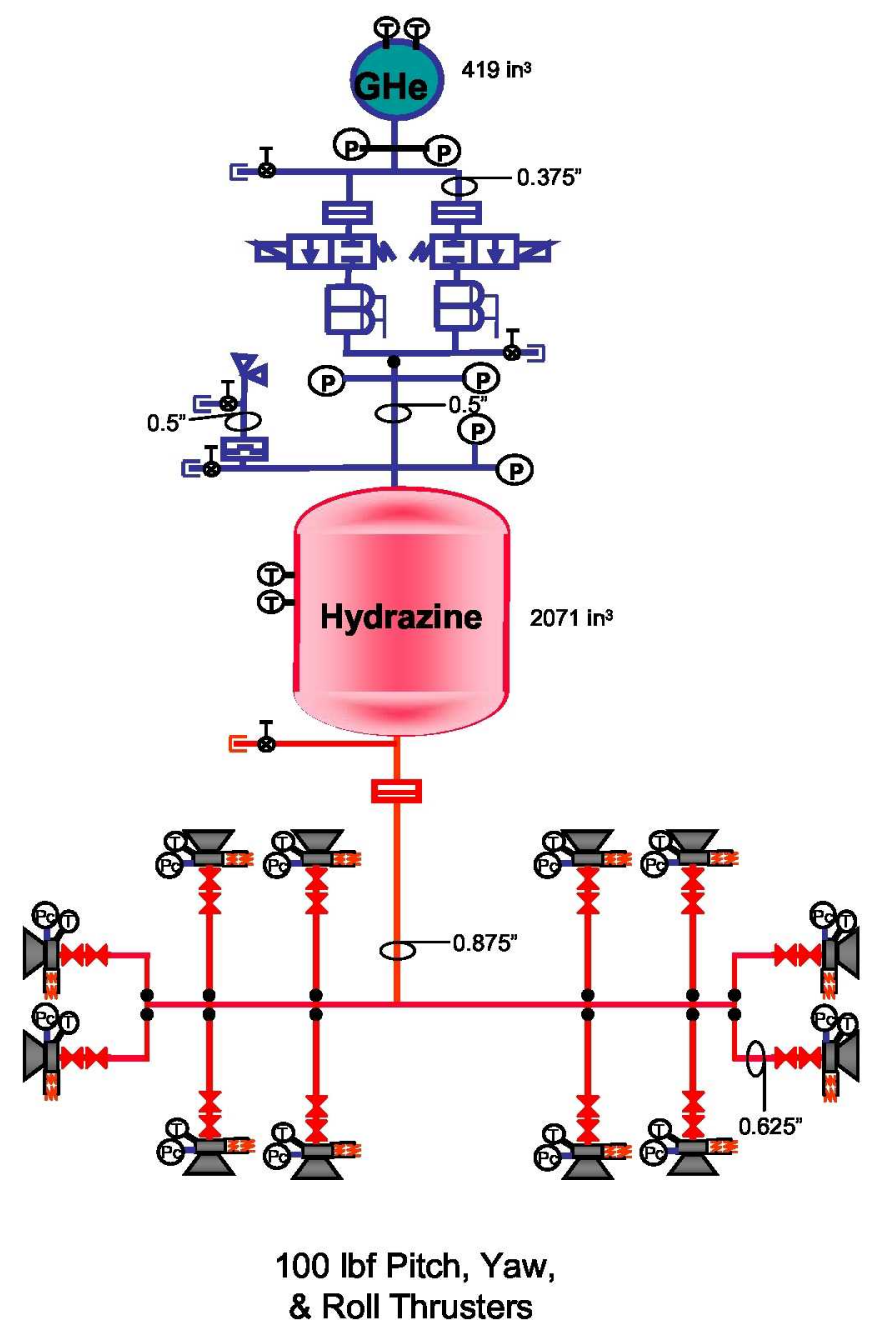

Figure 21. Design Analysis Cycle - 1B_Exit Upper Stage Reaction Control System Schematic.

\section{Thruster Module Design}

At PDR, the US ReCS thruster module design consisted of mounting base plates, tubing, fittings, thrusters, insulation, thruster mounting plates and fairings as seen in Figure 22. This design also had two removable panels on the top surface of the fairing that provided access to all thruster valves and allowed for handling during transportation and instillation. The baselined fairing material at PDR was Aluminum 6061-T6, which was chosen over a fairing made of composite material. It was determined that a TPS was required to help protect the thruster module fairing from aerodynamic heating during vehicle ascent. Cork was chosen as the TPS material due to its low weight and wide range of application in the aerospace industry. During US ReCS buildup, the cork TPS is applied to the fairing before attachment to the aft skirt on the US element. Also, approximately one inch of insulation was added around each thruster to thermally isolate intra-module thermal effects during the short US ReCS mission operational duration. Finally at PDR, vibration isolators were added to each thruster to help mitigate a harsh vibroacoustic environment of $52 \mathrm{G}_{\mathrm{rms}}$. 


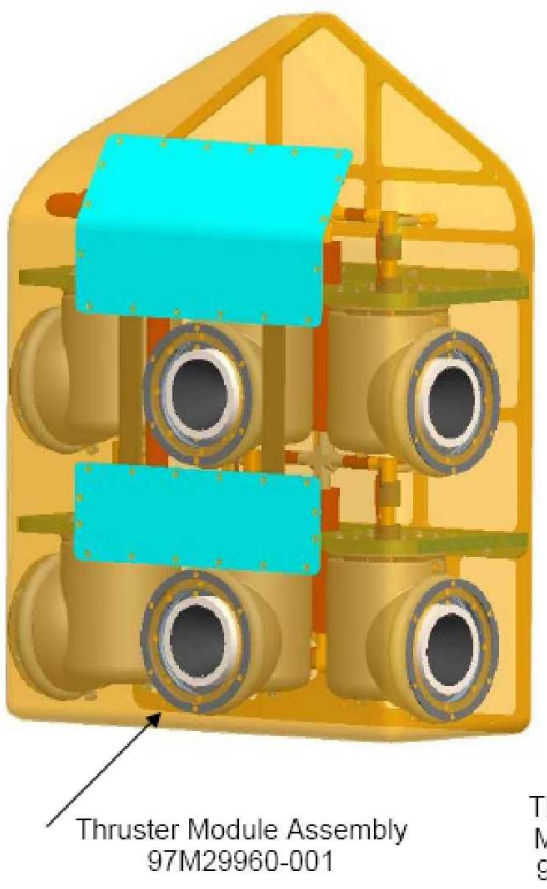
Mounting Plate 97M29962-001

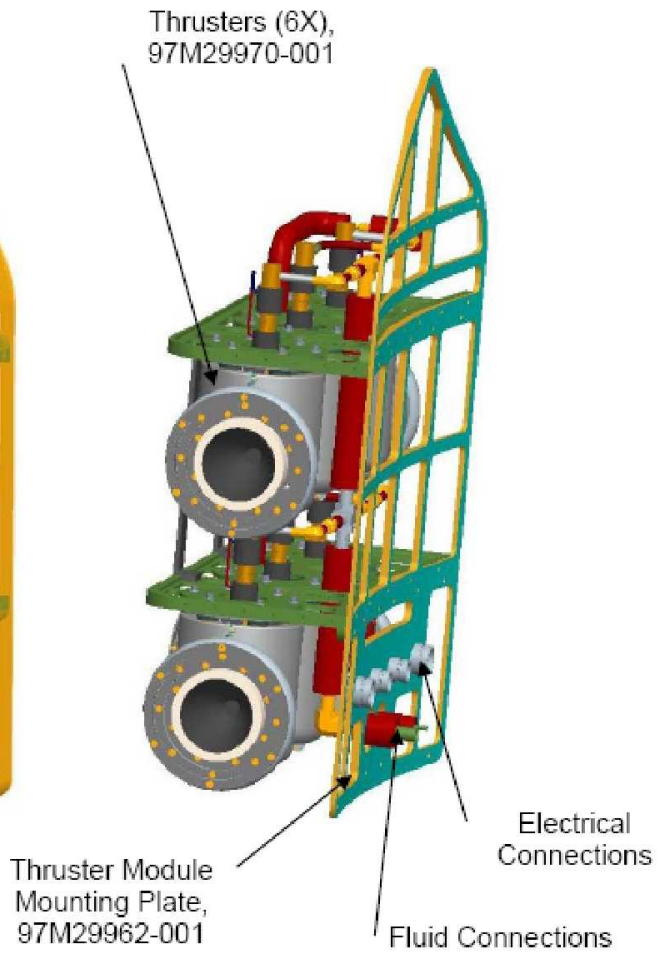

Figure 22. Preliminary Design Review Upper Stage Reaction Control System Thruster Module.

Since PDR, multiple aerodynamic and aero-acoustic analyses have been run on the US ReCS thruster module to determine fidelity of the design and its performance. Results from multiple Computational Fluid Dynamics analyses indicate that both the US ReCS PDR and post-PDR fairings aggravated the aero-acoustic environment. This was due to both fairing designs being composed of flat surfaces and sharp angles, which are prone to have excessive flow compressions and expansions with multiple aerodynamic shocks and flow separations. Based on those analyses, a fairing with ogive geometry was proposed and accepted because of its potential to help improve both the aerodynamic drag, as well as the aero-acoustic environments. The ogive geometry is the common shape for projectile design and has been demonstrated to improve aerodynamic performance by decreasing drag and lowering aerodynamic and transitions loads. Also, the two removable panels on the top surface of the PDR fairing have been removed from the design because they were no longer needed for transportation and handling of the US ReCS thruster module, as discussed below.

The PDR (and preferred) method for installing the US ReCS thruster modules called for assembling and closing them out on a bench before mounting them to the aft skirt from the outside of the vehicle. This method was modified due to the lack of space available for wrench access between the aft skirt and aft end of the LOX dome. The current method for installing the US ReCS thruster modules still calls for assembling them on a bench, but differs since they will mount to the aft skirt with the fairing off. The bolts used to mount the thruster modules will not face towards the vehicle, as in the PDR design, but will now face away from the vehicle to allow for wrench access to secure them. Once the thruster modules are secure to the aft skirt, they are closed out. Two CAD models of the current DAC-3A_S_RevA US ReCS thruster module with ogive geometry and without thruster insulation is shown in Figure 23. 

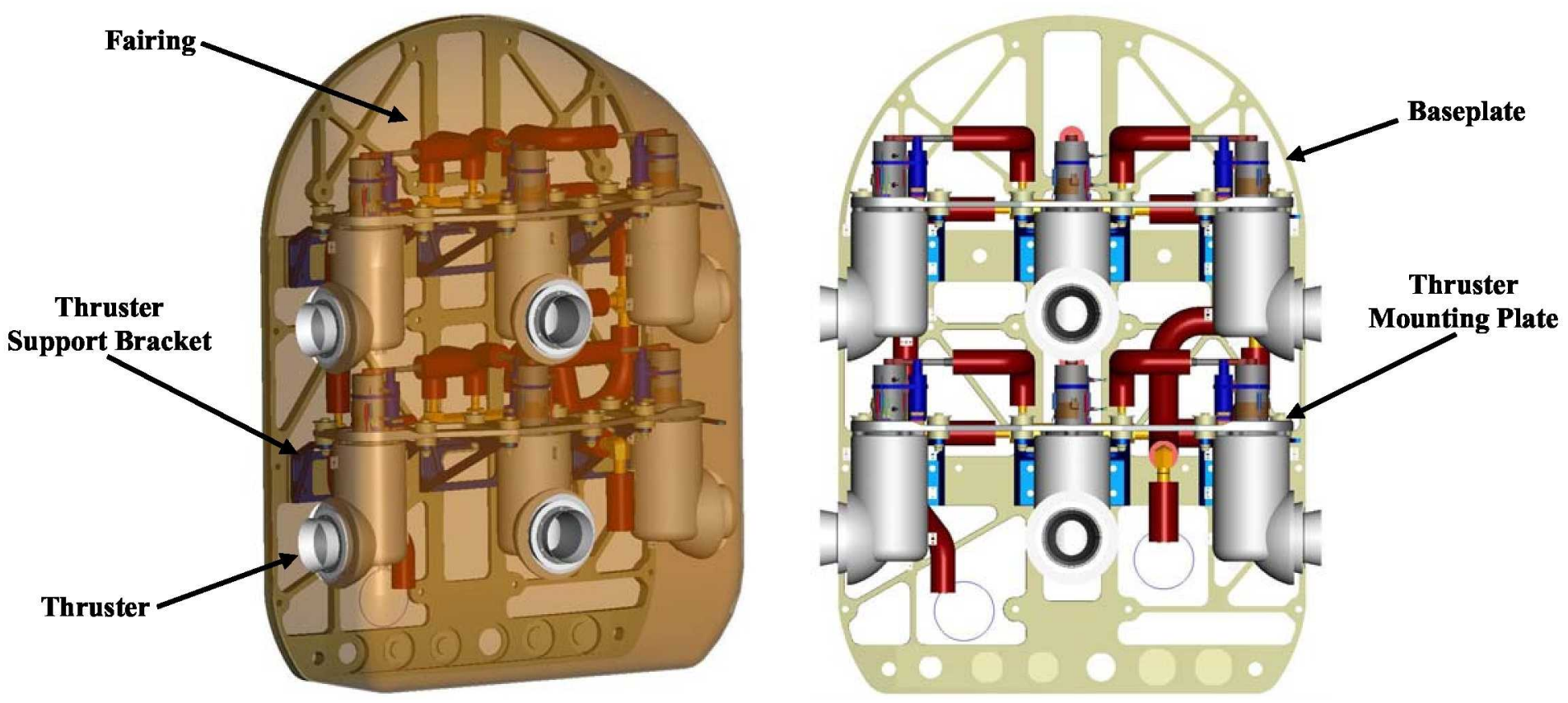

Figure 23. Design Analysis Cycle-3A_Start_Revision A Upper Stage Reaction Control System Thruster Module.

\section{Reduction in Thruster Area Ratio}

As the US ReCS design has matured, multiple issues arose that led to a review of the area ratio of the US ReCS thruster. Until August 2008, the area ratio of the US ReCS thruster has been 30:1, but due to large system dry mass that exceeded allocation and vibration/drag loads an area ratio assessment was performed. By reducing the area ratio of the US ReCS thruster, the individual mass of each thruster would decrease allowing the thruster modules to shorten in both length and width. These changes helped lower the total dry mass of the US ReCS. Reduction of the size of the thruster modules would possibly allow for a reduction in vibration and drag loads due to a smaller frontal and wetted module area. Also, as the study progressed, it was determined that a thruster with an area ratio of 15:1 could still meet the total impulse, inlet pressure, and $\mathrm{I}_{\mathrm{sp}}$ performance requirements for the US ReCS with the current usable propellant load and only a slight increase in supply pressure ( $20 \mathrm{psia})$. Therefore, the area ratio of the US ReCS thruster has been reduced from 30:1 to 15:1.

\section{Checkout/Servicing Approaches}

In recent months, work has been accomplished by the RCS NDT on multiple checkout and servicing approaches for both the FS RoCS and US ReCS. These approaches consist of:

- Checkout and inspections at Michoud Assembly Facility (MAF) during buildup and acceptance testing.

- Checkout and inspections in the Vehicle Assembly Building at Kennedy Space Center (KSC).

- Servicing and de-servicing on the Launch Pad at KSC.

Checkout will consist of multiple inspections and tests that will occur both in the VAB and on the Launch Pad to confirm that each system is ready for operation. A summary of the baseline checkout, servicing, and de-servicing approaches for the US ReCS is presented below.

Currently, there are two different servicing options being reviewed as methods to load and prepare the US ReCS for launch. Also, when the US ReCS must be de-serviced, three different contingency scenarios have been developed along with possible decontamination operations that would reduce $\mathrm{N}_{2} \mathrm{H}_{4}$ contamination to an acceptable working level. Finally, this work has assisted in maturing US ReCS ground operations and testing plans along with the vehicle timeline.

\section{Checkout}

Checkout of the US ReCS will begin during buildup and acceptance testing of the system at MAF. It is during that time that the workmanship and required performance capability of the US ReCS is confirmed. Before the US 
ReCS leaves MAF, final acceptance of the system will be conducted by either a direct probing accumulation method or pressure decay test at MEOP to determine a quantitative system level leakage rate. Once the US ReCS meets the required system level leakage rate, a blanket pressure of $100 \mathrm{psig}$ will be applied for transportation by barge from MAF to KSC. When the US element arrives at KSC it will be taken into the VAB where specific inspections and tests will be performed to verify that the US ReCS had not been damaged during shipping and still meets system requirements. The US element will then be integrated to the FS SRB and the CEV before being rolled out to the Launch Pad where it is then prepared for $\mathrm{N}_{2} \mathrm{H}_{4}$ and GHe servicing.

\section{Servicing}

Once at the Launch Pad, US ReCS fluid servicing preparations will begin before any $\mathrm{N}_{2} \mathrm{H}_{4}$ or $\mathrm{GHe}$ is loaded. In the current timeline it is estimated to take approximately eight hours to prepare the US ReCS for fluid servicing, four hours to load $\mathrm{N}_{2} \mathrm{H}_{4}$, and approximately two or three hours to load GHe. The current Launch Pad servicing preparations consist of the following:

- GSE transport and setup.

- Vehicle preparations.

- Final preparations.

- Non-hazardous pre-operations - Non-hazardous GSE preparations.

- Clear Launch Pad for hazardous operations.

- Hazardous pre-operations.

The current $\mathrm{N}_{2} \mathrm{H}_{4}$ loading method is under review, but it includes the use of scales to measure the loaded propellant. KSC has inquired about the use of a flow meter in lieu of scales to measure loaded propellant. There is concern about potential impact to flight hardware since GSE loading accuracy is unknown at this time, but is estimated as $< \pm 2 \%$. After servicing preparations are complete, $\mathrm{N}_{2} \mathrm{H}_{4}$ loading operations will begin with verifying/establishing the US ReCS configuration and venting the blanket pressure. $\mathrm{N}_{2} \mathrm{H}_{4}$ loading operations will likely follow one of the two recommended processes:

- Option one.

- Vent both sides of the propellant tank diaphragm to 30 psia.

- Maintain pressurant system at $30+20 /-0$ psia (TBR) during propellant fill operations.

- Vent propellant system to $10 \mathrm{psia}$ (TBR) to verify propellant diaphragm is in aft orientation.

$\circ$ Evacuate the propellant system to $\leq .5$ psia.

- Leak test propellant system.

- Backfill GSE with propellant.

- Take propellant sample.

- Verify propellant is within thermal limits $\left(70-100^{\circ} \mathrm{F}\right)$ prior to loading.

- Load $43.6 \mathrm{lbm} \pm .5 \%$ (TBR) propellant.

- Secure GSE and flight hardware.

- Pressurize propellant tank ullage volume to $100 \mathrm{psia} \pm 5 \mathrm{psia}$ (TBR) GHe.

- Secure GSE and flight hardware.

- Hazardous post-operations.

- Option two - KSC recommended process.

- Vent both sides of the propellant tank diaphragm to $30 \mathrm{psia}$.

- Vent propellant system to $10 \mathrm{psia}$ (TBR) to verify propellant diaphragm is in aft orientation.

$\circ$ Evacuate the propellant system to $\leq .5$ psia.

- Leak test propellant system.

- Evacuate/reduce pressure system to TBD psia (>1 psia). Lock up pressurant system.

- Final ullage pressure is approximately seven times higher than the initial ullage pressure.

- Very high driving pressure required to load propellant.

- Backfill GSE with propellant.

- Take propellant sample.

- Verify propellant is within thermal limits $\left(70-100^{\circ} \mathrm{F}\right)$ prior to loading.

- Load $43.6 \mathrm{lbm} \pm .5 \%$ (TBR) propellant.

- Secure GSE and flight hardware.

- Pressurize propellant tank ullage volume to $100 \mathrm{psia} \pm 5 \mathrm{psia}$ (TBR) GHe.

- Secure GSE and flight hardware.

- Hazardous post-operations. 
Upon successful completion of the $\mathrm{N}_{2} \mathrm{H}_{4}$ loading operations, GHe would be loaded based on the following sequence:

- Setup GSE for loading GHe.

- Take GHe sample.

- Hazardous operations.

- Secure and remove GSE.

With both $\mathrm{N}_{2} \mathrm{H}_{4}$ and GHe loading operations complete, the service valves will be prepared for flight, closeout photos taken and the service valve panel cover will be installed. Following successful closeout of the US ReCS, post-servicing monitoring will begin.

\section{De-servicing}

Should the situation of rolling back the Ares I launch vehicle from the Launch Pad to the VAB arises, the US ReCS must be properly de-serviced to allow for any work to take place on the system or vehicle. Currently, three possible contingency scenarios have been defined:

- Rollback with $\mathrm{N}_{2} \mathrm{H}_{4}$ and GHe loaded.

- Approach used if anomaly does not involve any subsystem residing in the interstage.

- Assumes US element is not returned to MAF

- Rollback with $\mathrm{N}_{2} \mathrm{H}_{4}$ loaded, but GHe vented.

- Approach used if anomaly involves a system internal to the interstage, but not the US ReCS.

- Assumes US element is not returned to MAF.

- Venting GHe is a hazardous operation due to GHe contamination from $\mathrm{N}_{2} \mathrm{H}_{4}$ migration across the propellant tank diaphragm.

- Vent GHe and eliminate all liquid $\mathrm{N}_{2} \mathrm{H}_{4}$ prior to rollback.

- Approach used if anomaly found in the US ReCS.

- Assumes US element must be returned to MAF.

- Acceptable vapor concentration is TBD.

A consideration that may alter these possible contingency scenarios is a 100 day Launch Pad limit requirement. Also, decontamination operations have been developed to reduce all liquid $\mathrm{N}_{2} \mathrm{H}_{4}$ contamination to an acceptable working level prior to rollback. The current decontamination operations process consists of the following:

- Vent GHe.

- De-tank liquid $\mathrm{N}_{2} \mathrm{H}_{4}$.

- Continuous $\mathrm{GN}_{2}$ purge until $\mathrm{N}_{2} \mathrm{H}_{4}$ is removed.

- Use of warm $\mathrm{GN}_{2}$ and flight heaters will help evaporate liquid $\mathrm{N}_{2} \mathrm{H}_{4}$.

- Remove propellant tank on Launch Pad if required to attain lower contamination levels.

- Can reduce contamination to TBD levels, but cannot guarantee that level will be received by MAF.

- Soft goods will off gas, raising $\mathrm{N}_{2} \mathrm{H}_{4}$ concentration level.

- Must develop process for decontamination of US ReCS prior to shipment to MAF.

\section{Test and Verification Approach}

This section outlines the completed, ongoing, and anticipated test programs as part of the overall verification and qualification approach for the FS RoCS and US ReCS designs. Results from these advanced development, flight development, and flight qualification tests is planned to anchor the multitude of design analyses and to verify system requirements.

\section{A. Advanced Development}

\section{First Stage Roll Control System Thruster Feasibility Test}

To mitigate risk associated with the lack of test or flight heritage with high-thrust, pulsing monopropellant $\mathrm{N}_{2} \mathrm{H}_{4}$ thrusters, a series of pulse-mode tests (using the MSL heritage throttling decent engines) were successfully conducted at Aerojet, Sacramento to prove feasibility in December, 2006. See Section II for more details.

\section{Waterhammer Testing}

In order to complete early benchmarking of the fluid analysis model (MSC Inc. software EASY5 ${ }^{\mathrm{TM}}$ ), a series of water flow tests were performed. The tests were conducted to characterize the transient pressure spikes associated the rapid closing of valves, i.e. waterhammer. Using flight similar configurations and components for both FS 
RoCS and US ReCS, testing was performed to demonstrate the effectiveness of a surge arrestor to mitigate waterhammer pressure effects. The surge arrestor was a gas-filled pressure vessel being separated from the propellant simulant via a welded metal bellows. The sealed gas acts as an accumulator to dampen the waterhammer pressure waves. The test series explored the effects of various surge arrestor gas pressures, surge arrestor locations relative to the thruster valves, and various tank pressures on the effectiveness of surge pressure dampening. Further testing is planned as part of the FS RoCS and US ReCS System Development Test Article (SDTA) test programs (see below).

\section{Advanced Development Hardware Testing}

A number of component vendors were sent Requests For Information early on in the design process to both ascertain the availability of suitable existing designs with flight heritage, as well as to identify the most critical components for which further development testing was desired. For the FS RoCS the most critical components (aside from the thrusters) were determined to be the thruster valves, pressure regulators, and propellant isolation valves. For the US ReCS, thruster valves and propellant isolation valves were at the top of the list. A number of study contracts were begun with various component vendors and the majority of them ended with the delivery of development hardware to NASA, designed to the flight-like system performance characteristics. A follow on test program was conducted in house to characterize component performance, compare designs from different vendors, and help develop the component flight specifications. Additional study contracts were initiated for the FS RoCS propellant tanks, and pressurant tanks, and the US ReCS thruster assembly and propellant tank.

\section{B. Flight Development}

\section{System Development Test Article}

The FS RoCS and US ReCS SDTA are cold-flow fluid system simulators, consisting of flight-similar tanks, plumbing, system valves, and thruster valves. The objectives of these development test programs are to obtain fluid system performance data for a flight representative configuration, to evaluate integrated system level performance characteristics, and to verify analytical models as a part of the critical design activities. The test results of the SDTAs are essential in validating the performance and interaction of the RoCS and ReCS and anchoring analysis tools and results to a CDR level of fidelity. No further system level tests are planned until system level qualification testing, planned for 2012 and 2013 (see below). The propellant and pressurization system dynamics and associated thermal performance will be demonstrated over the range of operational temperatures, pressures, and simulated Mission Duty Cycles (MDCs). Additionally, system loading and unloading tests will be conducted to mature the procedures and methodology for the ground based servicing functions. Flight-like hardware will also be evaluated under expected operating conditions to identify any potential performance concerns early. De-Ionized water, with similar fluid properties to $\mathrm{N}_{2} \mathrm{H}_{4}$, will be used to simulate the propellant.

Buildup of the FS RoCS SDTA began in December of 2008, with in-house construction and assembly completing in April, 2009. Preliminary checkout and system calibration testing had begun in May, with full system testing beginning in June and ending in mid-July. Detailed test objectives for the FS RoCS SDTA program included:

- Evaluate system surge pressure (waterhammer) characteristics due to thruster valve operation over a range of MDCs at nominal and MEOP.

- Evaluate temperature transients and heat transfer in the pressurization system, including regulator blowdown and propellant ullage performance.

- Measure system pressure drops for comparison to analysis of tubing and components.

- Validate system activation and re-activation procedures for the helium pressurant system and the simulated propellant system.

- Validate system processes for loading, unloading, and purging.

- Validate procedures and system response for multiple failure scenarios, including relief valve operation.

- Evaluate system performance for contingency scenarios in which six thrusters are being fired simultaneously.

A CAD layout of the FS RoCS SDTA and pictures of the test article integrated into the test cell are shown below in Figure 24 and 25, respectively. 


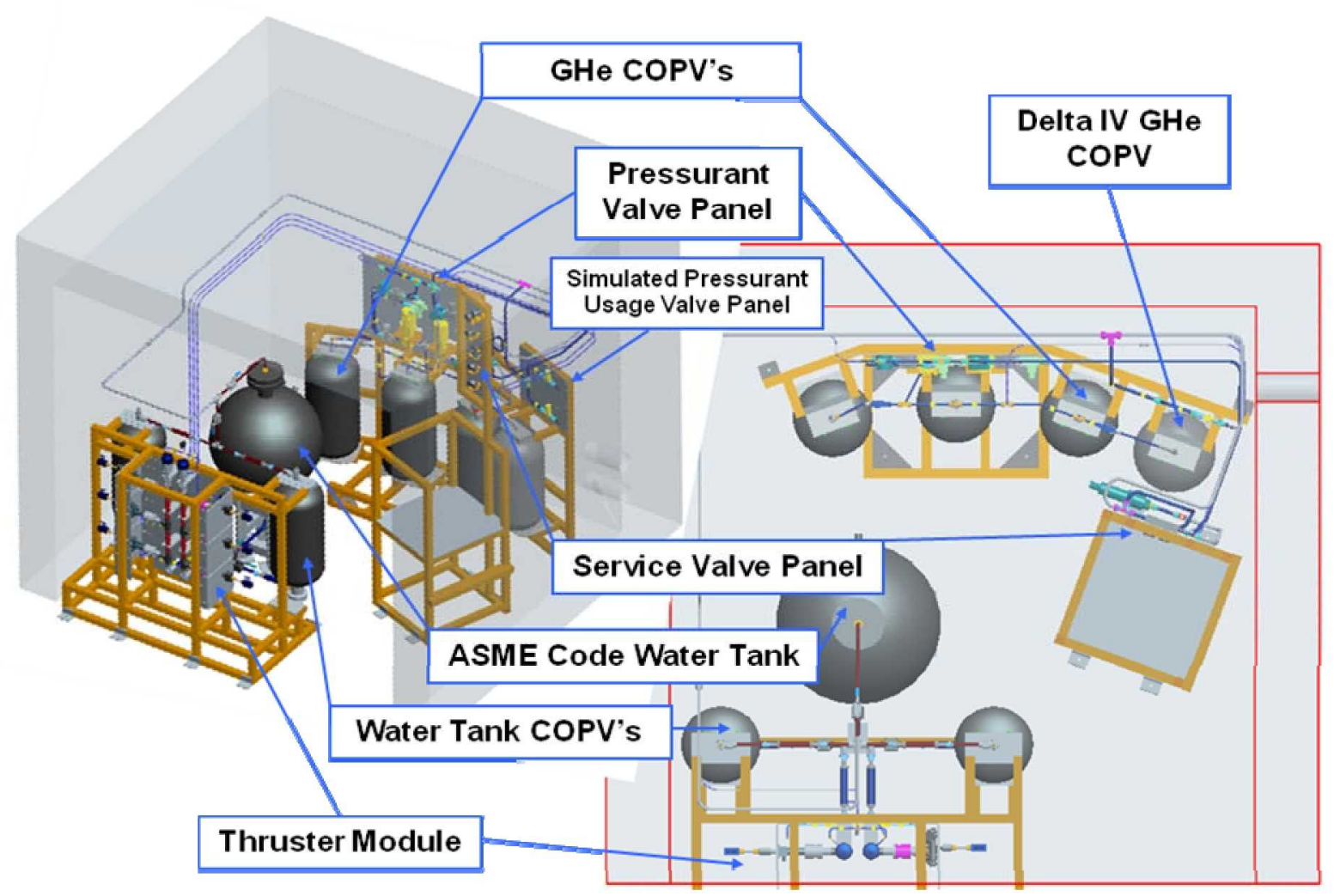

Figure 24. First Stage Roll Control System - System Development Test Article Computer Aided Design Model Test Cell Layout.
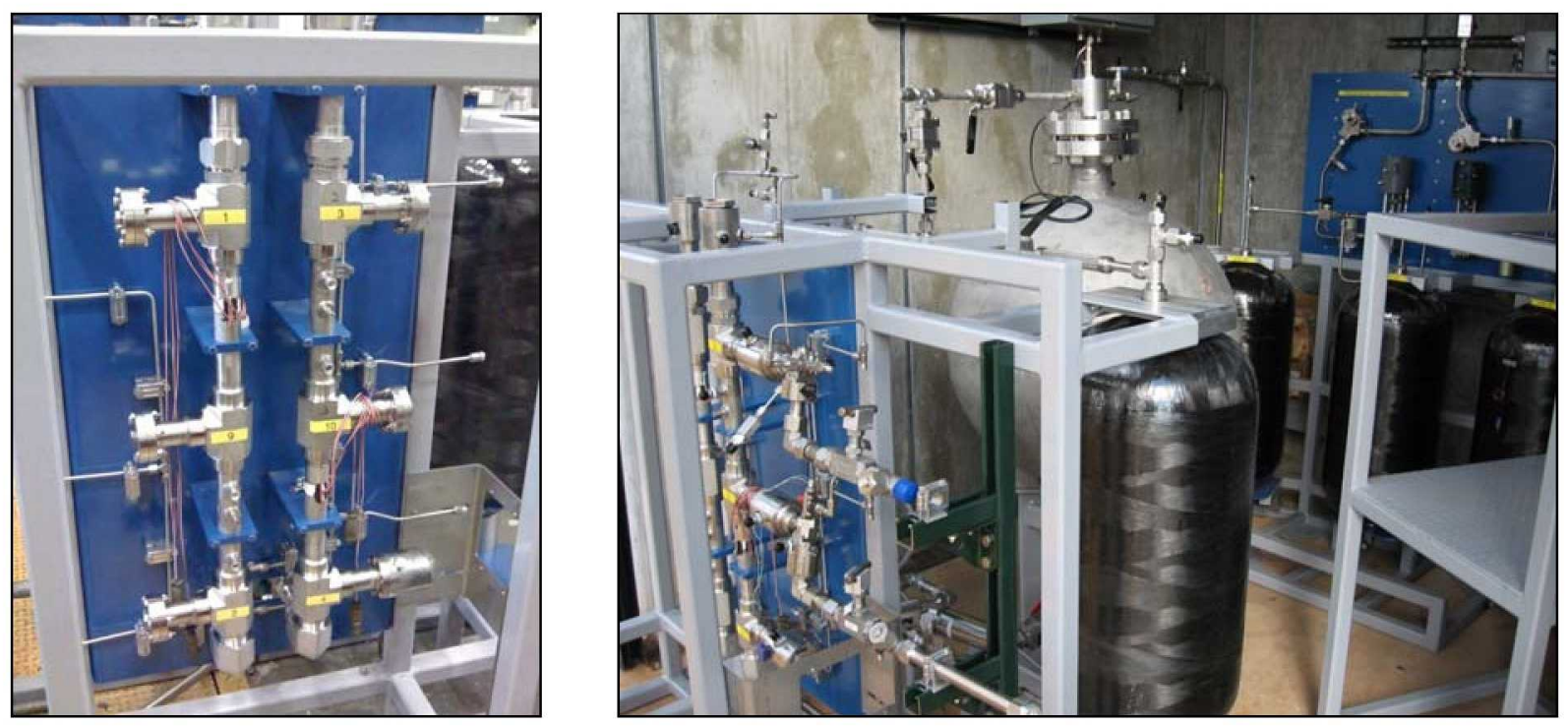

Figure 25. First Stage Roll Control System - System Development Test Article Hardware Integrated into Test Cell.

Test results are planned for discussion in future publications. The US ReCS SDTA has been constructed and is being integrated into a second test cell at NASA MSFC, with a month-long test program scheduled for August, 2009. 


\section{Component Development Testing}

Upon release of the Ares I RCS component specifications, the USPC will select and put under contract vendors for each component. Once selected, each SCI vendor will undergo the necessary design, development, test and engineering necessary to meet the requirements specified in the flight SCI specifications. Currently development build and test activities are planned for all RCS SCIs except for the FS RoCS and US ReCS propellant tanks, the FS RoCS pressurant tank, and the FS RoCS thruster (the latter of which is addressed below). Upon completion of the flight development phase, the SCI flight qualification phase will begin and a full shipset of each FS RoCS and US ReCS SCI is planned for delivery to the NDT for use in the subsystem environmental and full system level hot fire qualification testing (see below).

\section{First Stage Roll Control System Thruster Advanced Development Contract}

Due to the very limited flight heritage with the RoCS thruster a Advanced Development Contract (ADC) was initiated early in 2007. The primary purpose of the ADC was to design, build and test a prototype RoCS thruster with the intent of fulfilling the development phase of the Design, Development, Test and Engineering for the RoCS thruster and enable direct entry into the flight qualification phase. Hot-fire testing of the development engine is scheduled to begin early in 2009 and continue through the fall.

\section{Subsystem Development Testing}

Currently, a series of sub-assembly flight development tests are scheduled to address concerns with the high levels of predicted vibration and shock. A set of tests for both the FS RoCS and US ReCS will be conducted at the thruster module level using flight representative simulators to measure both induced environments at the SCI interface to validate the design features that are being incorporated to mitigate the vibration and shock loads to the thrusters, and to anchor analytical tools for dynamic response and stress conditions to a CDR level of fidelity. This is important, as the monopropellant $\mathrm{N}_{2} \mathrm{H}_{4}$ thrusters currently baselined can be susceptible to attrition (damage) to the catalyst at high vibration levels. Overall thruster assemblies are possibly susceptible to damage associated with the expected high shock environments associated with FS and US element separation. Similar vibration and shock development testing is planned for the US ReCS service panel sub-assembly. This is vital, as the monopropellant $\mathrm{N}_{2} \mathrm{H}_{4}$ thrusters currently baselined are possibly susceptible to attrition (damage) to the catalyst at high vibration levels.

\section{Flight Qualification}

\section{Source Controlled Item Qualification}

All SCIs will be qualification tested for expected flight environments, performance and life, by the respective vendors.

\section{Subsystem Environmental Qualification}

All subassemblies for the FS RoCS and US ReCS will undergo a series of environmental qualification tests as part of the overall system qualification. Subassemblies include thruster modules, service panels, and the FS pressurant valve panel. Each subassembly will undergo a series of thermal cycle and vacuum tests, vibration tests, and shock tests that will insure system functionality and design margins for all of the anticipated environments (except for thruster hot fire) during flight operations. Functionality and leakage will be conducted on each SCI within these subassemblies as part of these tests.

\section{Hot Fire Test Articles}

The FS RoCS and US ReCS Hot Fire Test Articles (HFTA) are full system level hot fire qualification test articles. The purposes of the HFTAs are to provide formal system level performance qualification testing for the FS RoCS and US ReCS, using flight qualified hardware. Testing is planned for simulated altitudes. Using flight SCIs, the HFTAs will also be used as pathfinders for the flight article manufacturing process along with test and check out operations. The full scale system test articles will be used to qualify system dynamic response, system thermal response, end-to-end system performance for anchoring models, system level response for various MDCs, activation and loading sequences, integrated pressurization system performance, and integrated fault detection and isolation. Testing is currently scheduled for 2012-2013 at the NASA White Sands Test Facility. 


\section{Conclusion}

Initial planning for the design and development of Ares I reaction control systems began in late 2005. A series of DACs were conducted over the last three years to develop the FS RoCS and US ReCS designs, based on iterative cycles of system requirements, predicted environments, and risk mitigation activities, to a level of fidelity suitable for a preliminary design. A successful PDR for the Ares I RCS occurred in April, 2008. Currently, system designs are being matured to the next program milestone, CDR, scheduled for the winter of 2010. Component and system development testing is underway and initiation of flight component development vendor selection is scheduled to begin in the summer of 2009 .

\section{Acknowledgments}

The authors gratefully acknowledge the kind assistance of Mr. Pat McRight and Mr. Chuck Pierce, Branch Chief and Deputy Branch Chief of the NASA MSFC Spacecraft and Auxiliary Propulsion Systems Branch (ER23). Also, the authors would like to thank Mr. Huu Trinh, NASA MSFC Senior Aerospace Engineer, for enabling the completion of this paper. Finally, the authors would like to recognize the RCS NDT for all of their encouragement, hard work, and provided support.

\section{References}

${ }^{1}$ Pierce, C. W., "First Stage Roll Control System Subsystem Description Document," National Aeronautics and Space Administration, Ares-USO-DE-25169, 2008.

${ }^{2}$ Jernigan, F. R., "Upper Stage Reaction Control System Subsystem Description Document," National Aeronautics and Space Administration, Ares-USO-DE-25168, 2008.

${ }^{3}$ Turpin, A. A., "First Stage Roll Control System Subsystem Design Specification," National Aeronautics and Space Administration, Ares-USO-SE-25719, 2008.

${ }^{4}$ Turpin, A. A., "Upper Stage Reaction Control Subsystem Design Specification," National Aeronautics and Space Administration, Ares-USO-SE-25718, 2008.

${ }^{5}$ Butt, A., Popp, C. G., Pitts, H. M., and Sharp, D. J., "NASA Ares I Launch Vehicle Roll and Reaction Control Systems Overview," Joint Army, Navy, NASA, Air Force Propulsion Meeting, JANNAF-SPS-I-17, Johns Hopkins University, Chemical Propulsion Information Analysis Center, Baltimore, MD, December 2008.

${ }^{6}$ Brown, C. D., Spacecraft Propulsion, AIAA Education Series, AIAA, Washington, DC, 1996, Chaps. 1, 4, and 5. 